\title{
Sweetening of the global diet, particularly beverages: patterns, trends, and policy responses
}

\author{
Barry M Popkin, Corinna Hawkes
}

\section{Key messages}

The addition of caloric sweeteners to foods and beverages is linked to an increased risk
of a range of cardiometabolic problems.

- Evidence of the cardiometabolic outcomes of beverages containing low-calorie sweeteners and 100\% fruit juice remains inconclusive.

- $68 \%$ of packaged foods and beverages available in the USA contain caloric sweeteners, $74 \%$ include both caloric and low-calorie sweeteners, and $5 \%$ include only low-calorie sweeteners.

- We expect that the US pattern of caloric sweeteners and low-calorie sweeteners in the food supply will also be seen in most high-income countries and around the world in the next few decades.

- In most low-income and middle-income countries, sales of sugar-sweetened beverages in daily calories per person are increasing, whereas intake is declining in a few high-income regions (eg, North America, Australasia, and western Europe).

- Because of the associated cardiometabolic risks, WHO and many countries are promoting a major reduction in intake of added caloric sweeteners.

- Governments around the world are increasingly developing and implementing policies that aim to reduce intake of sugar-sweetened beverages.

- Evidence from Mexico shows that taxation policies can be effective; other policies and regulations in Chile and other countries are too new to be assessed.
}

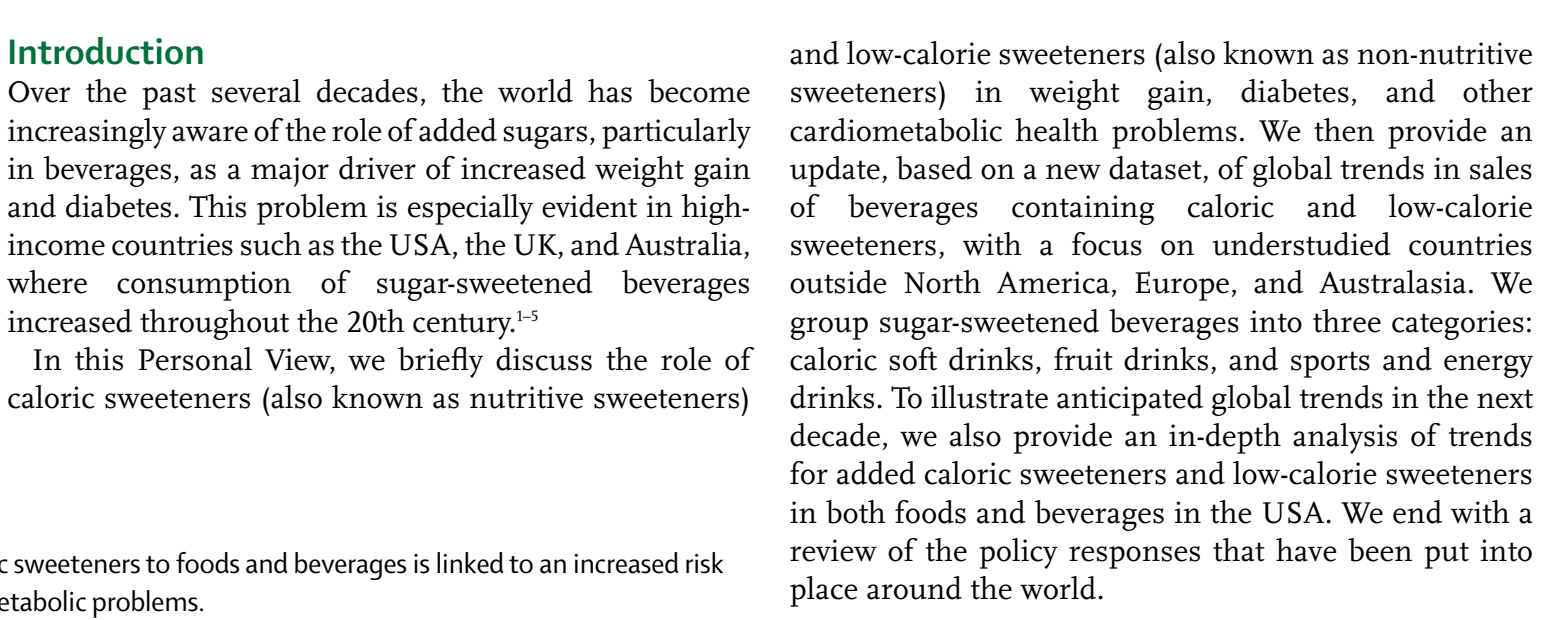

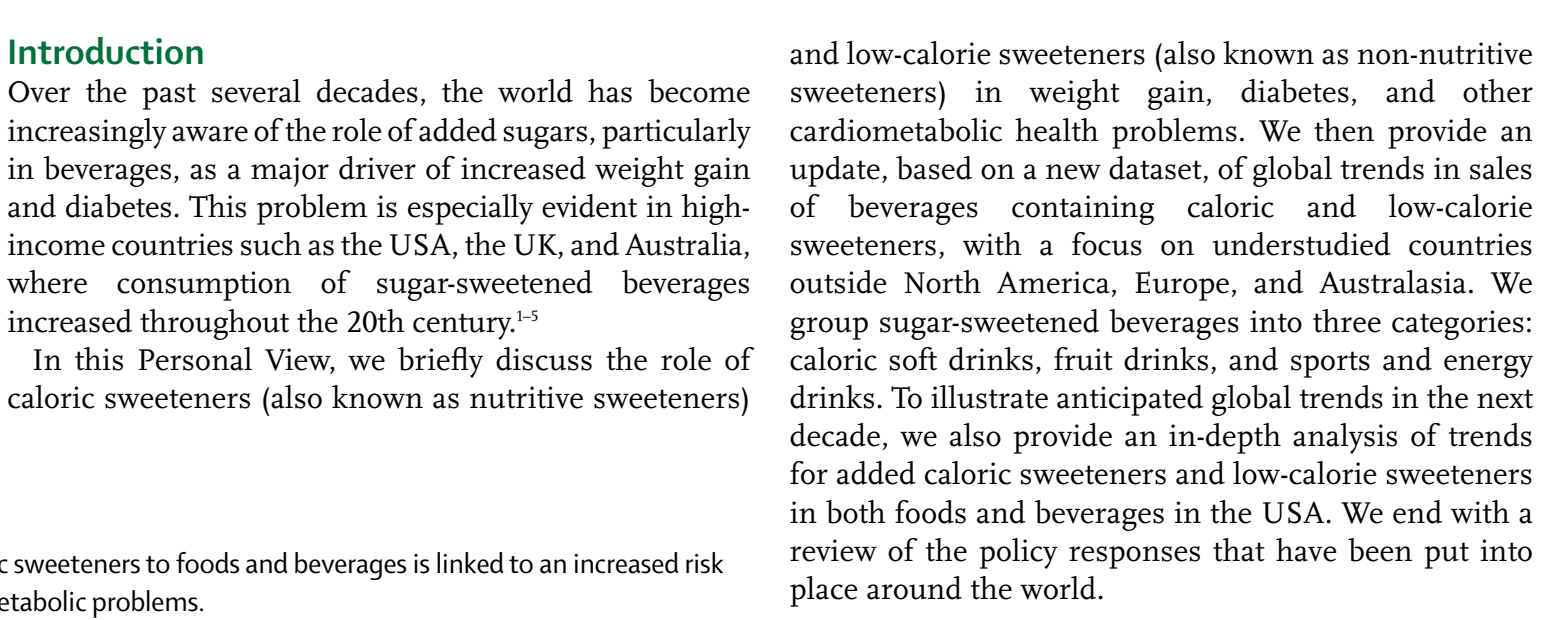

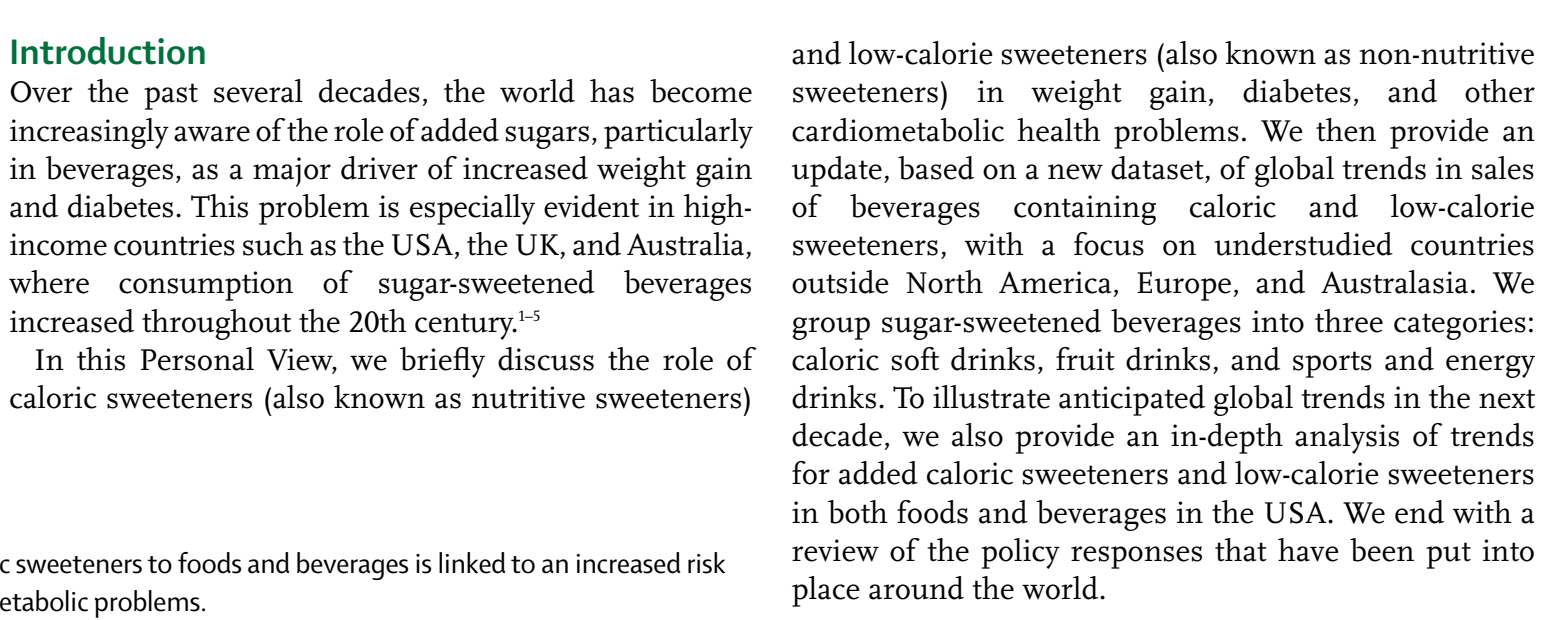

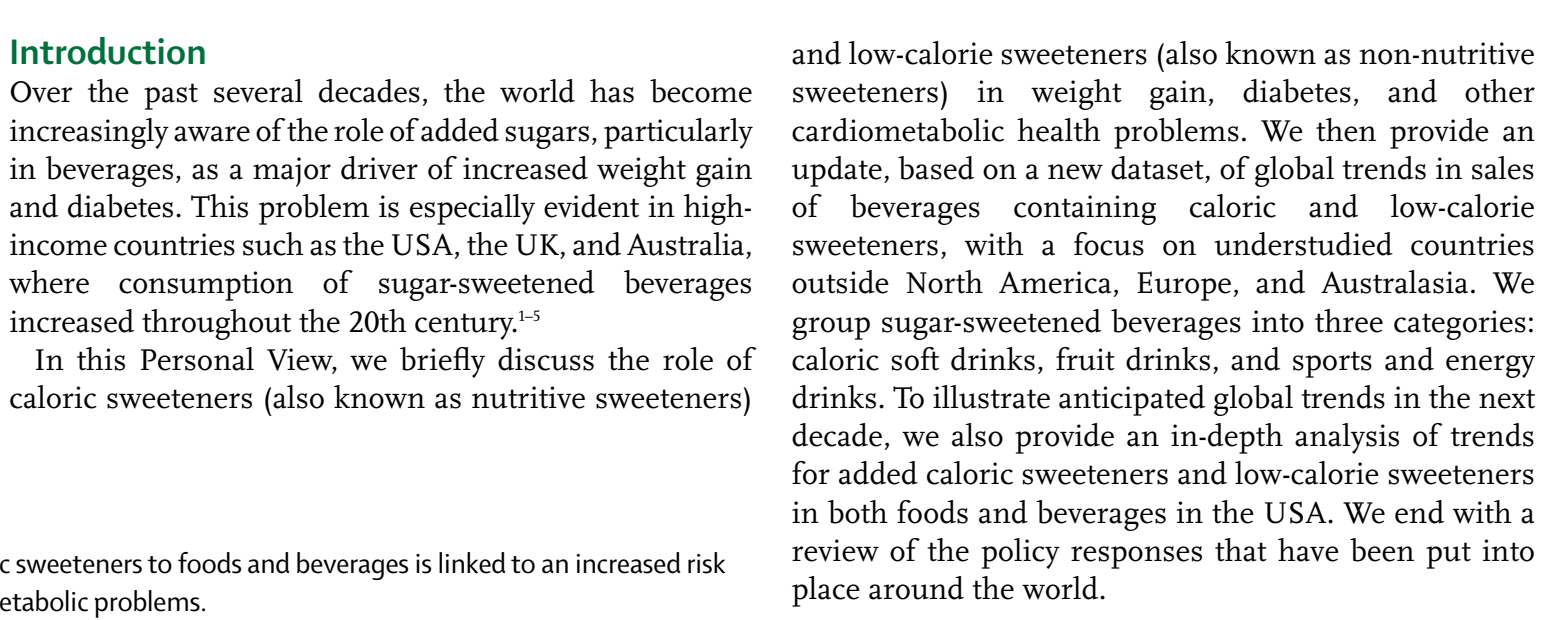

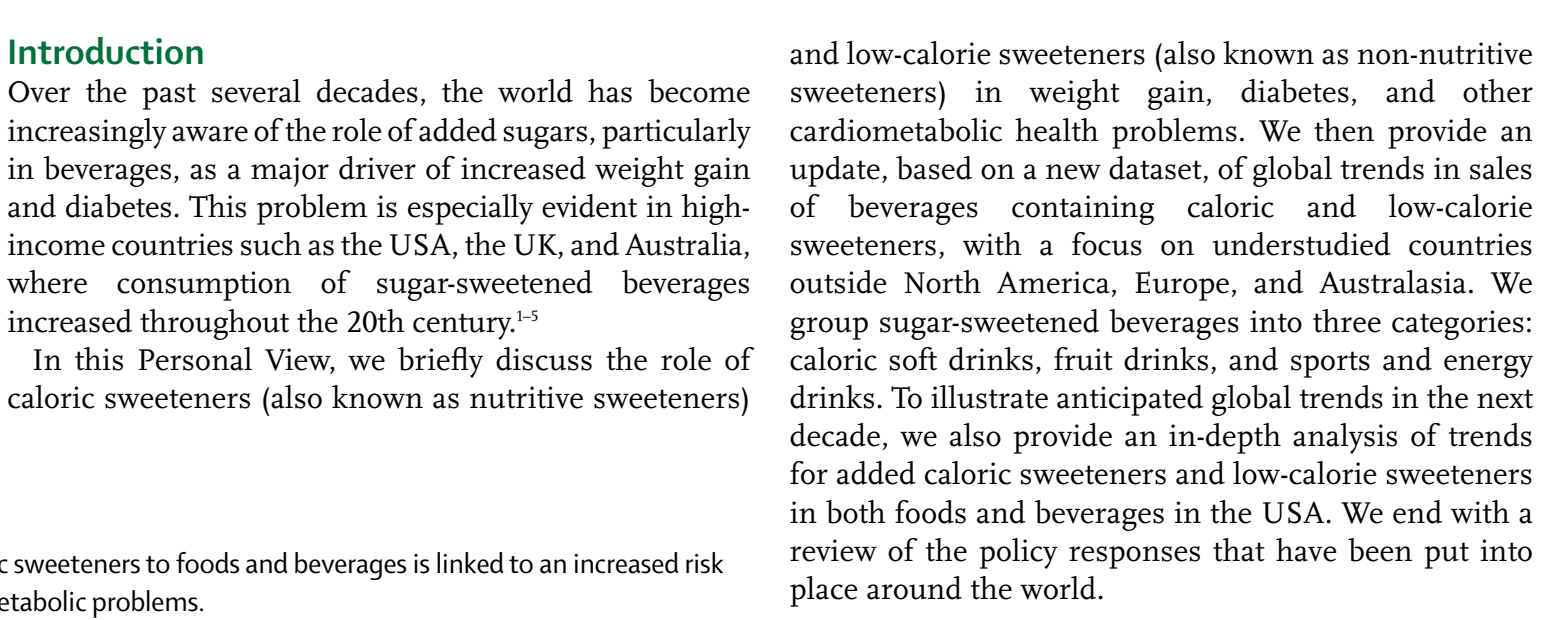

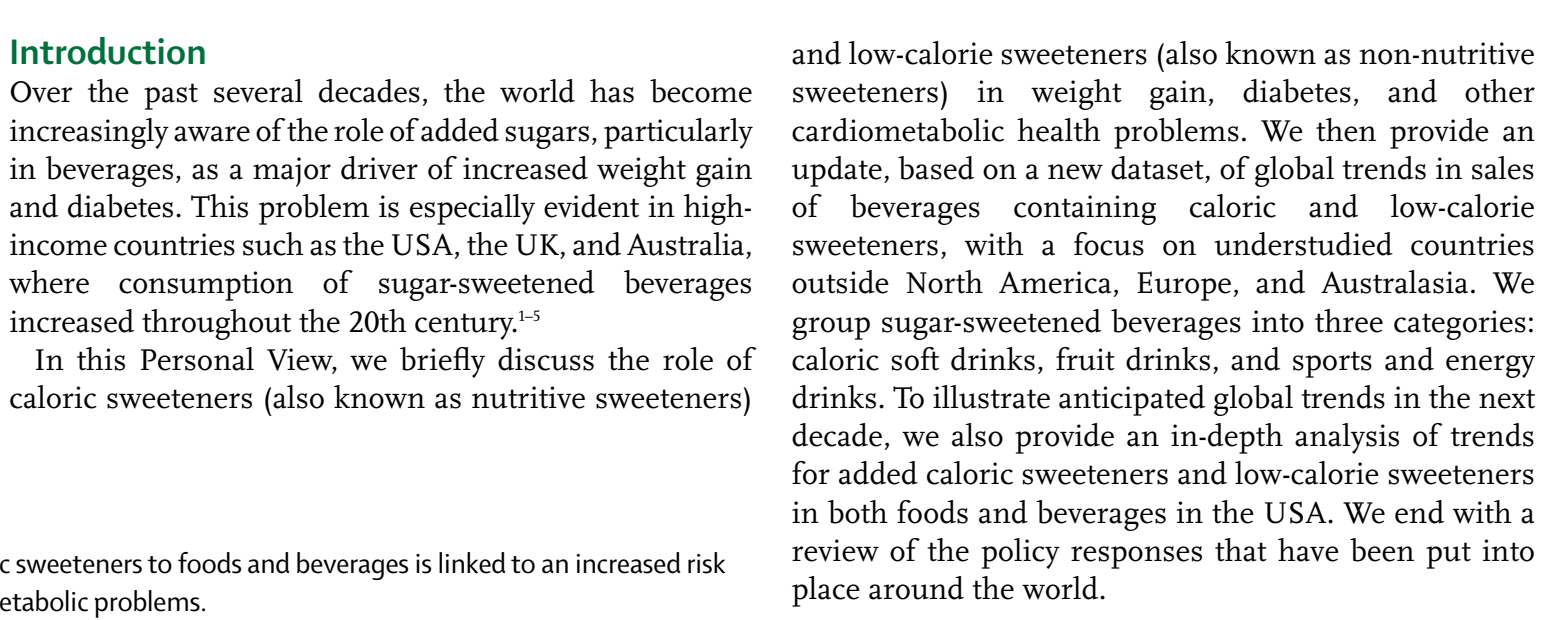

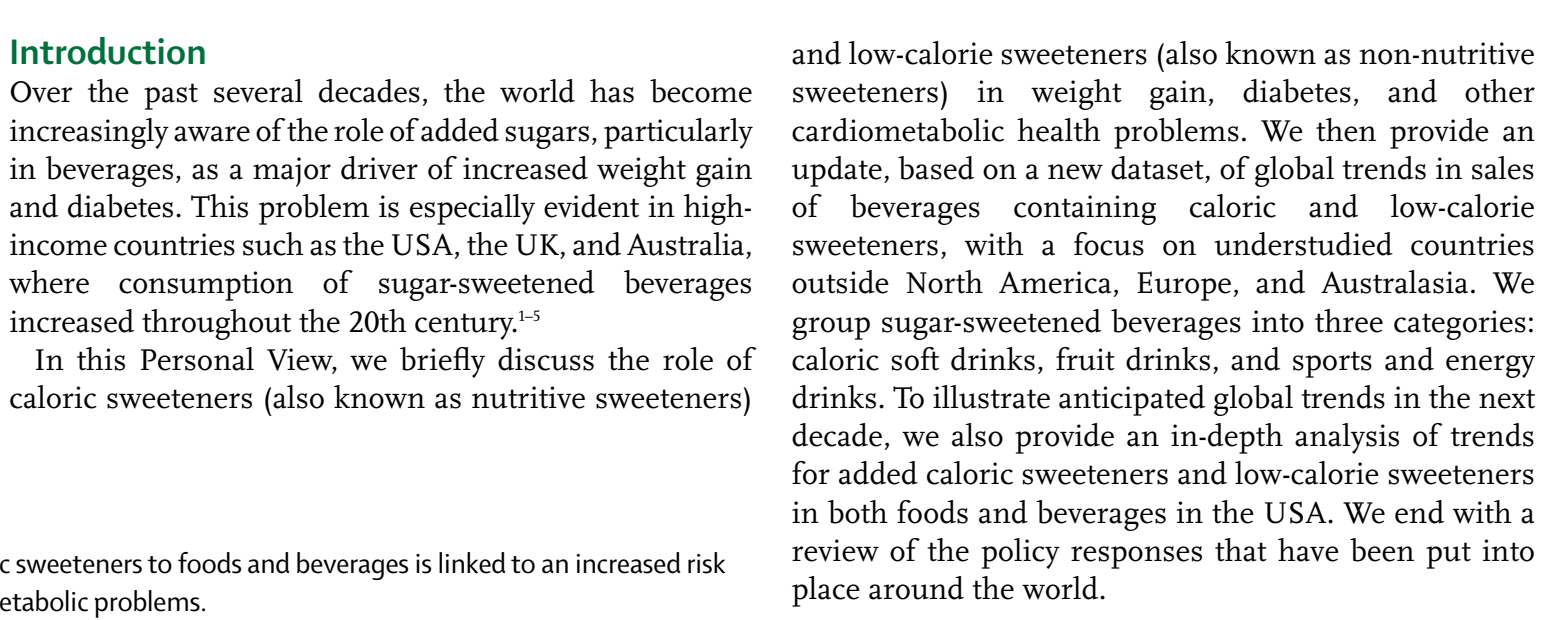

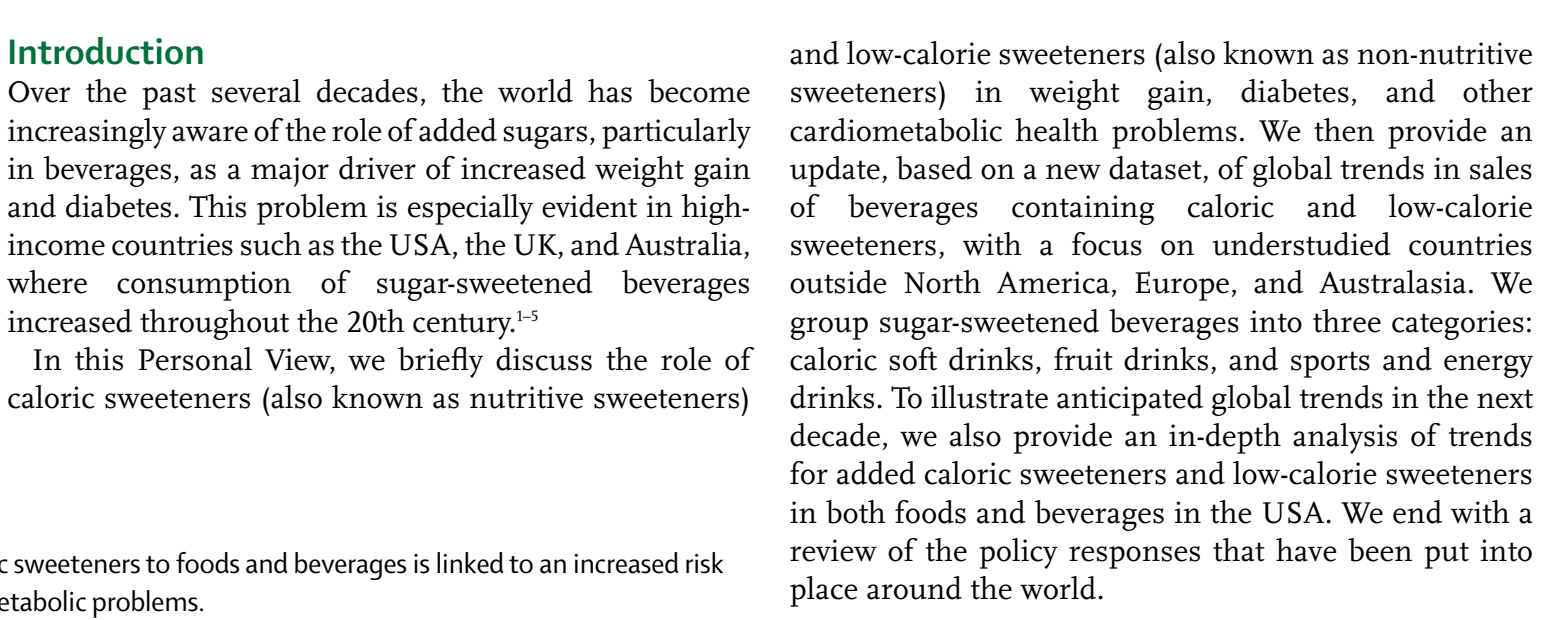

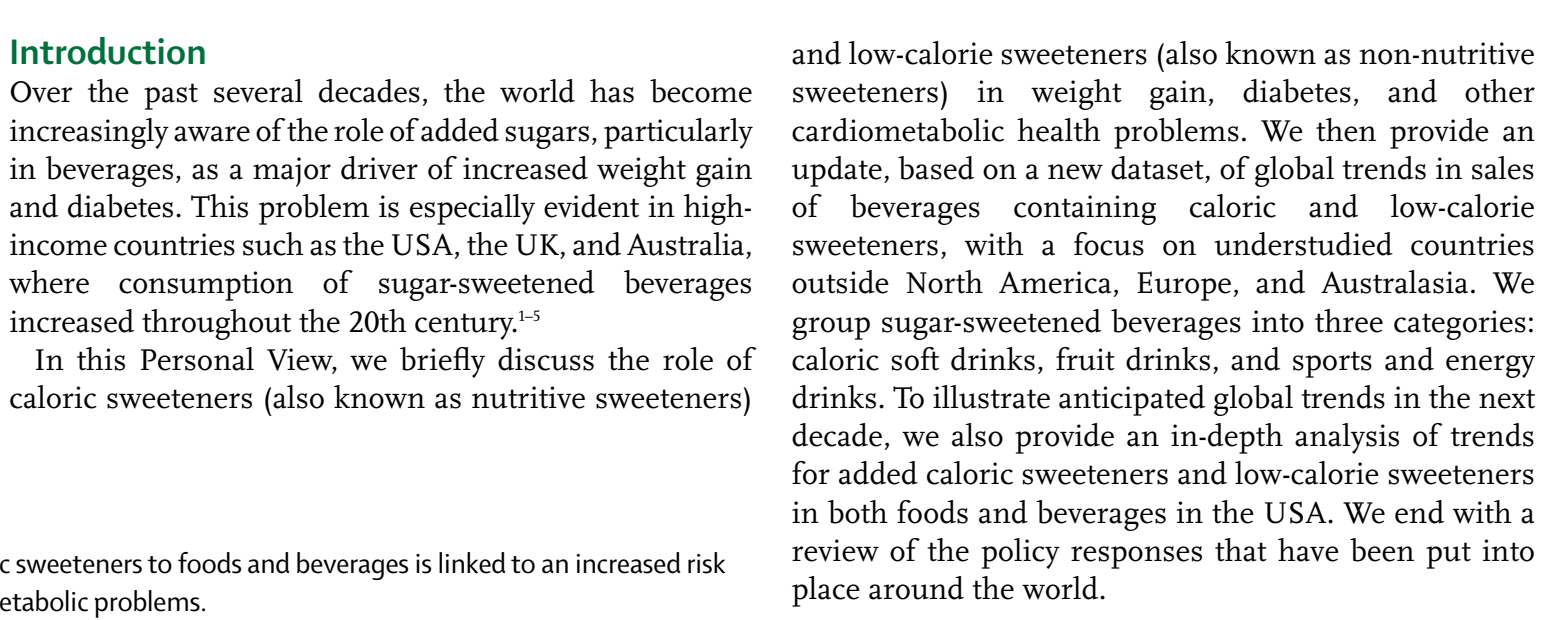

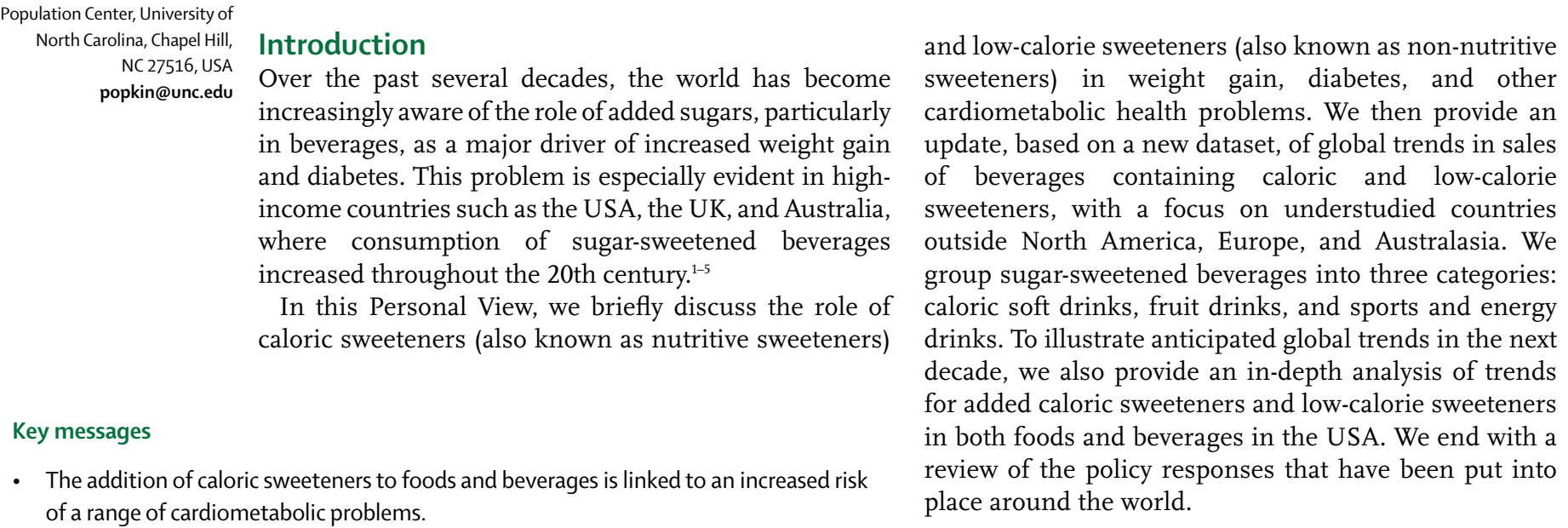

\section{Cardiometabolic effects of caloric and low-calorie sweeteners \\ The past 25 years have seen a revolution in our understanding of the effect of caloric sweeteners (including sugar) on energy intake, obesity, and diabetes. Although the relation between sugar and insulin control has been understood since the $1920 \mathrm{~s},{ }^{6}$ appeals to view sugar as a danger to health were ignored by most of the health profession during the 1950s and 1960s.${ }^{7.8}$ Public health and biomedical scholars' focus on sugar-sweetened beverages increased substantially after groundbreaking work by Richard Mattes and others showing that intake of caloric beverages in any form are not compensated for by an equivalent reduction in food intake. ${ }^{-12}$ Although the reason behind this finding is not fully understood, some potential biological mechanisms (eg, an evolutionary explanation centred on the extreme}

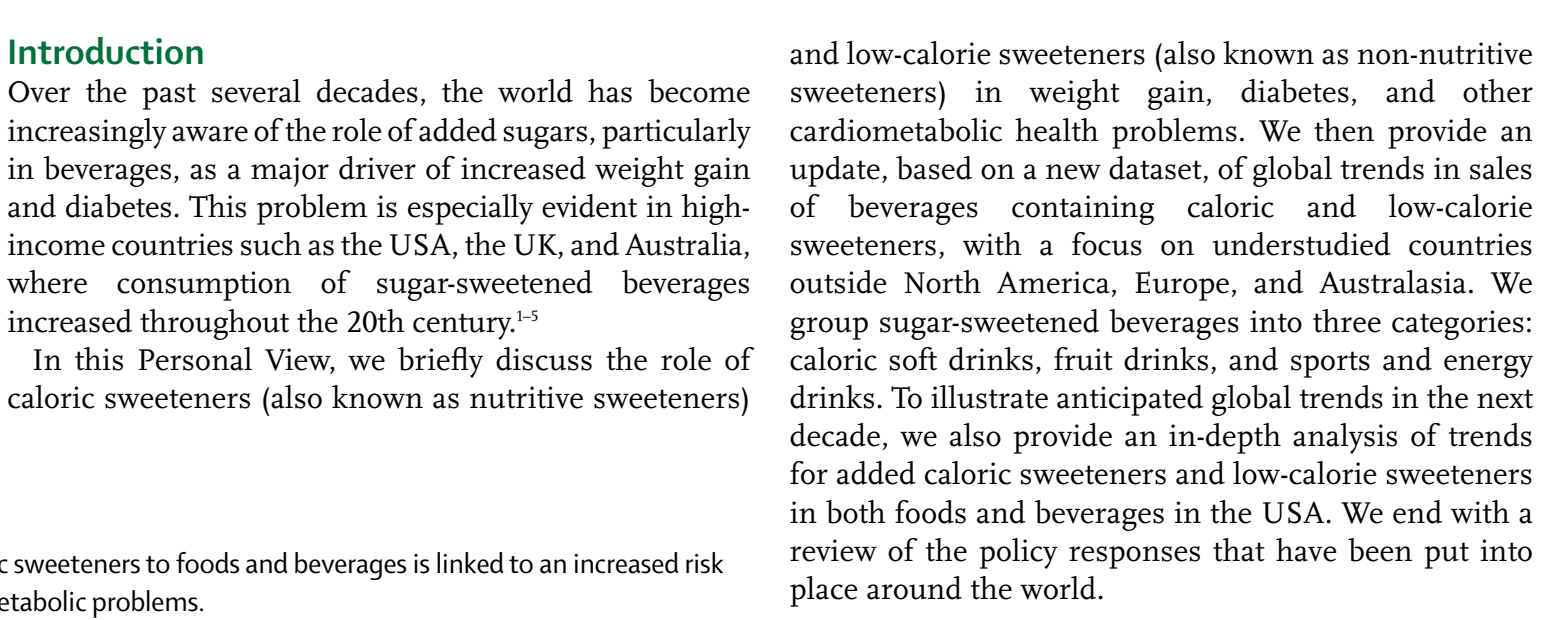

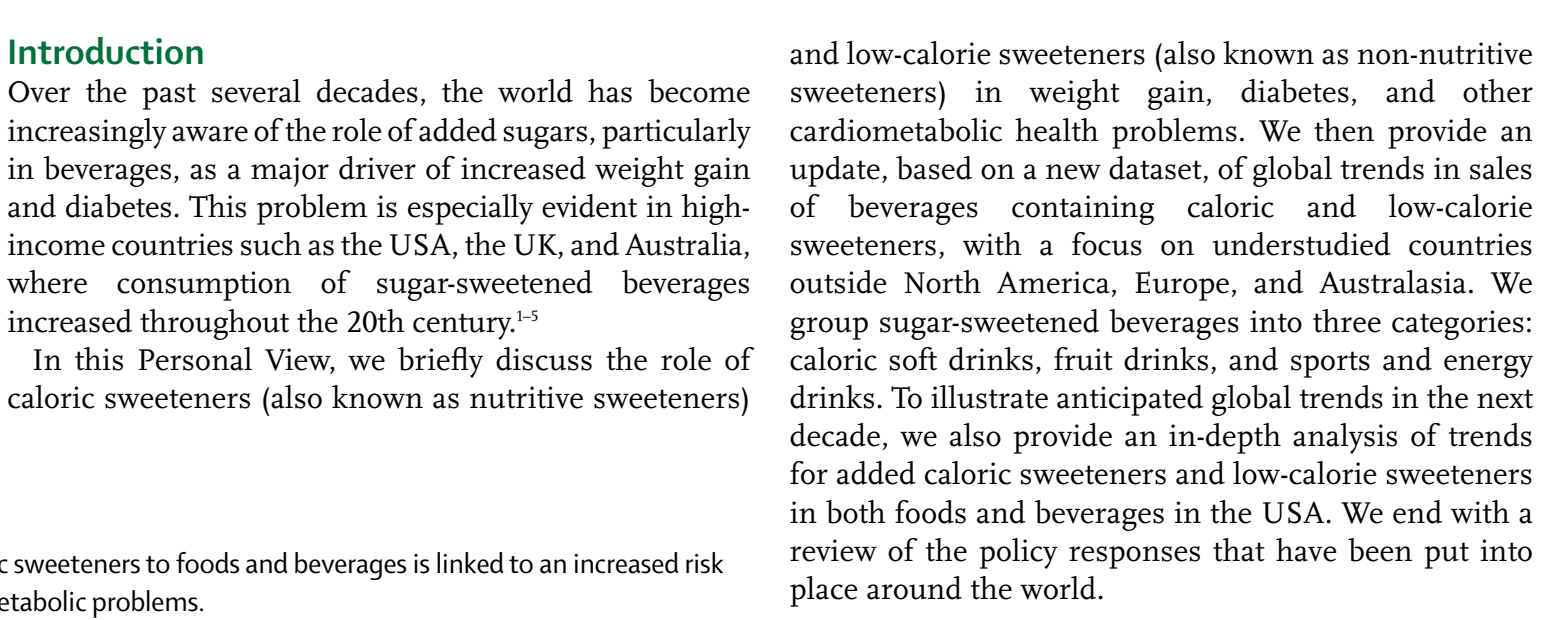

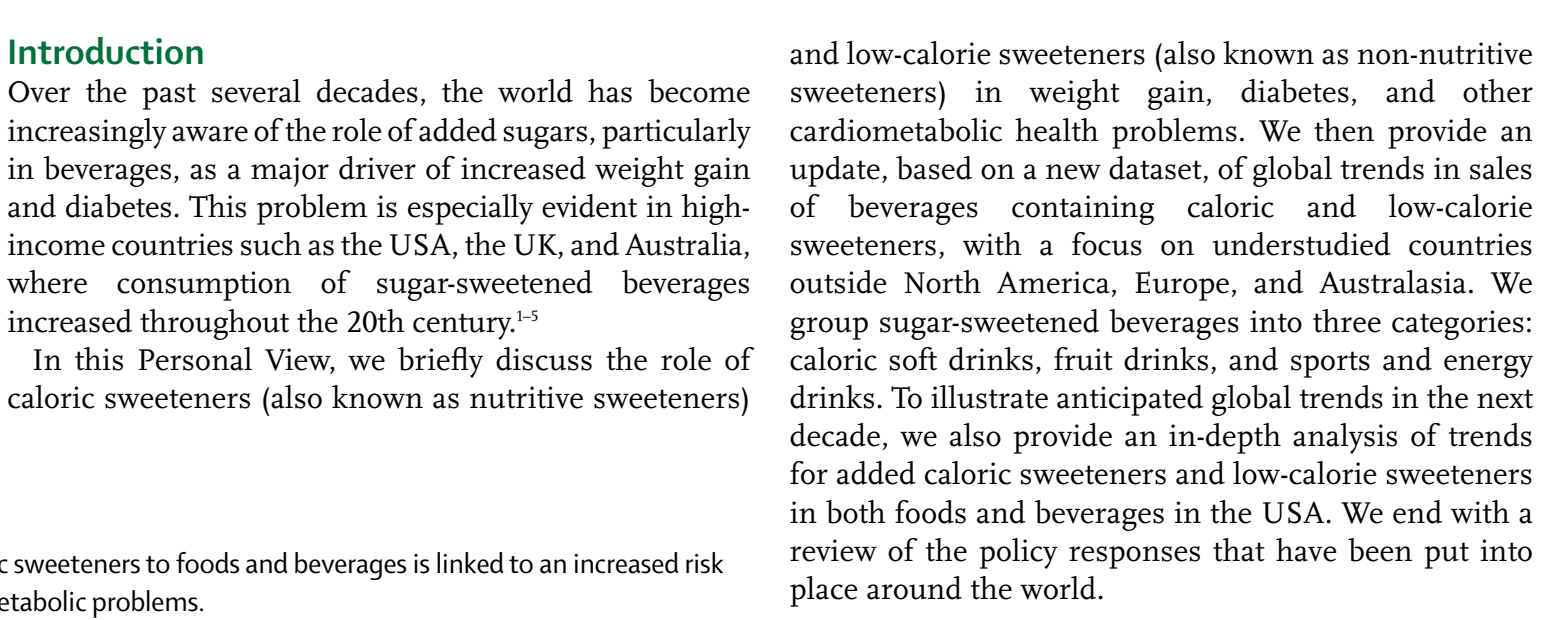

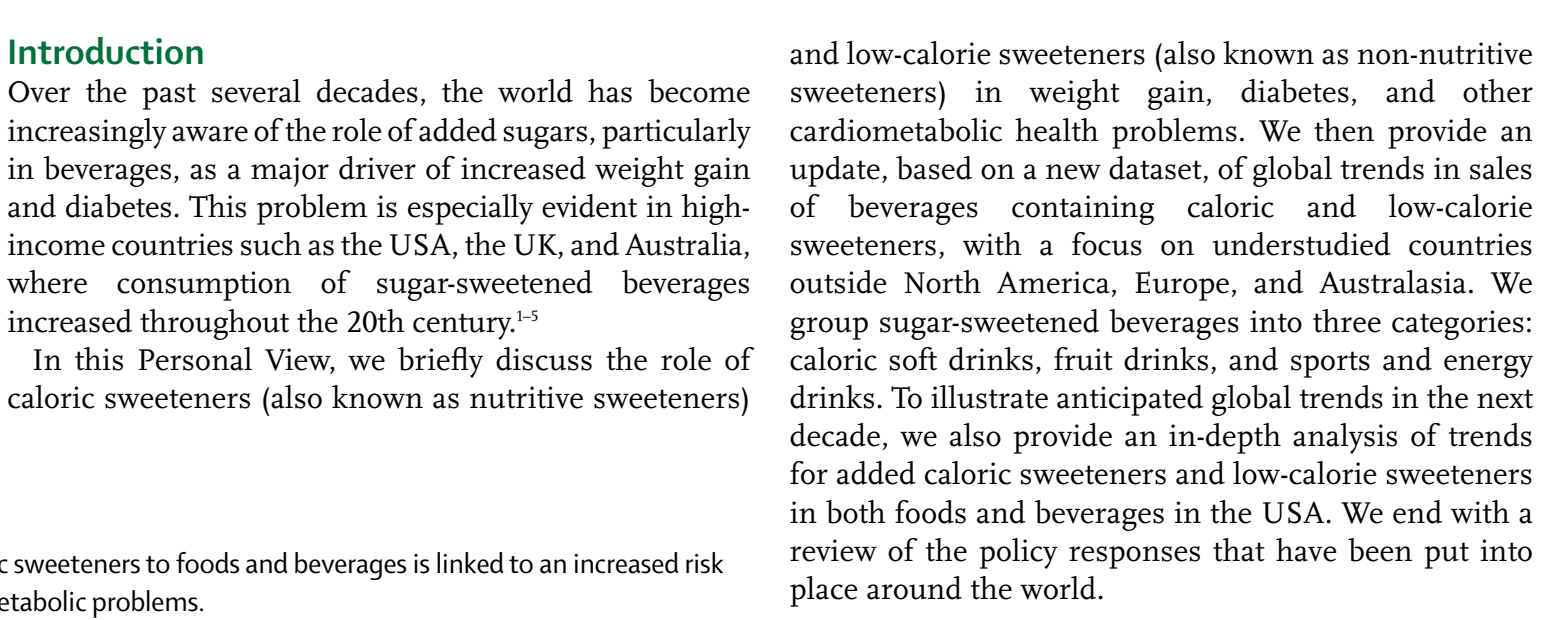

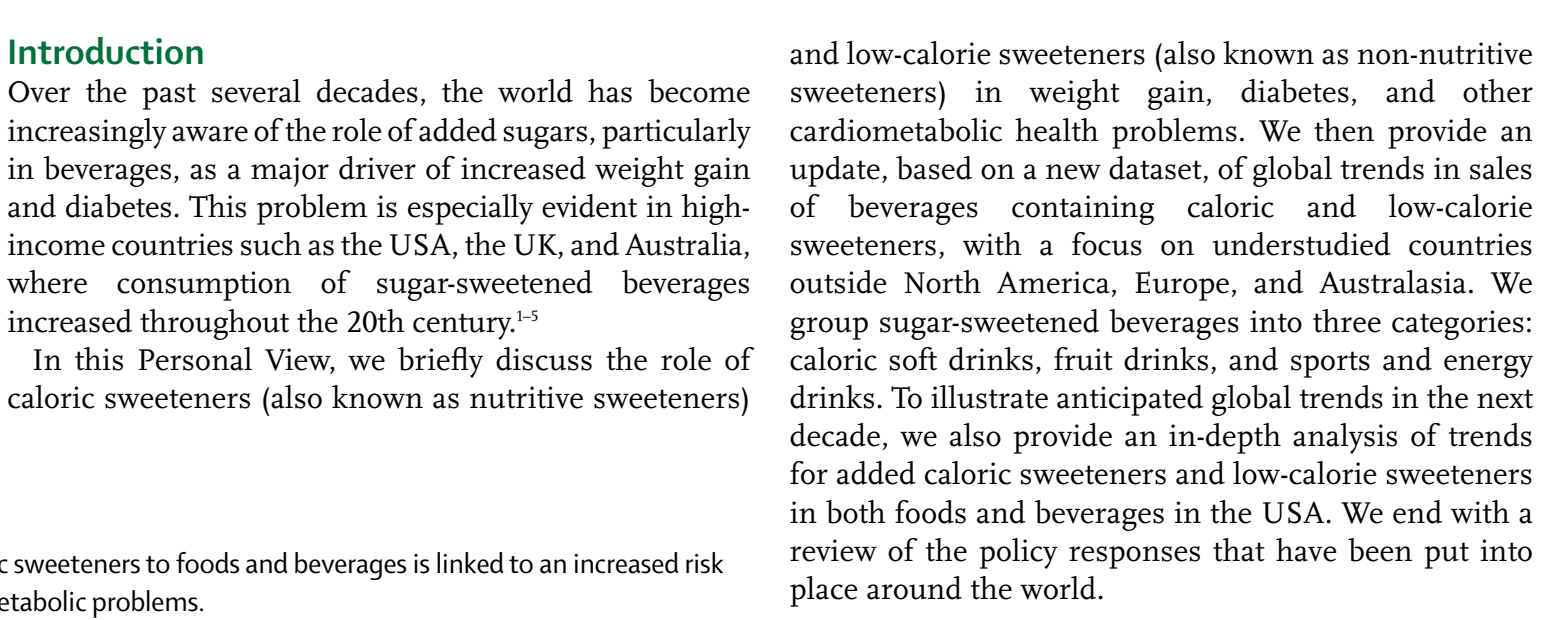

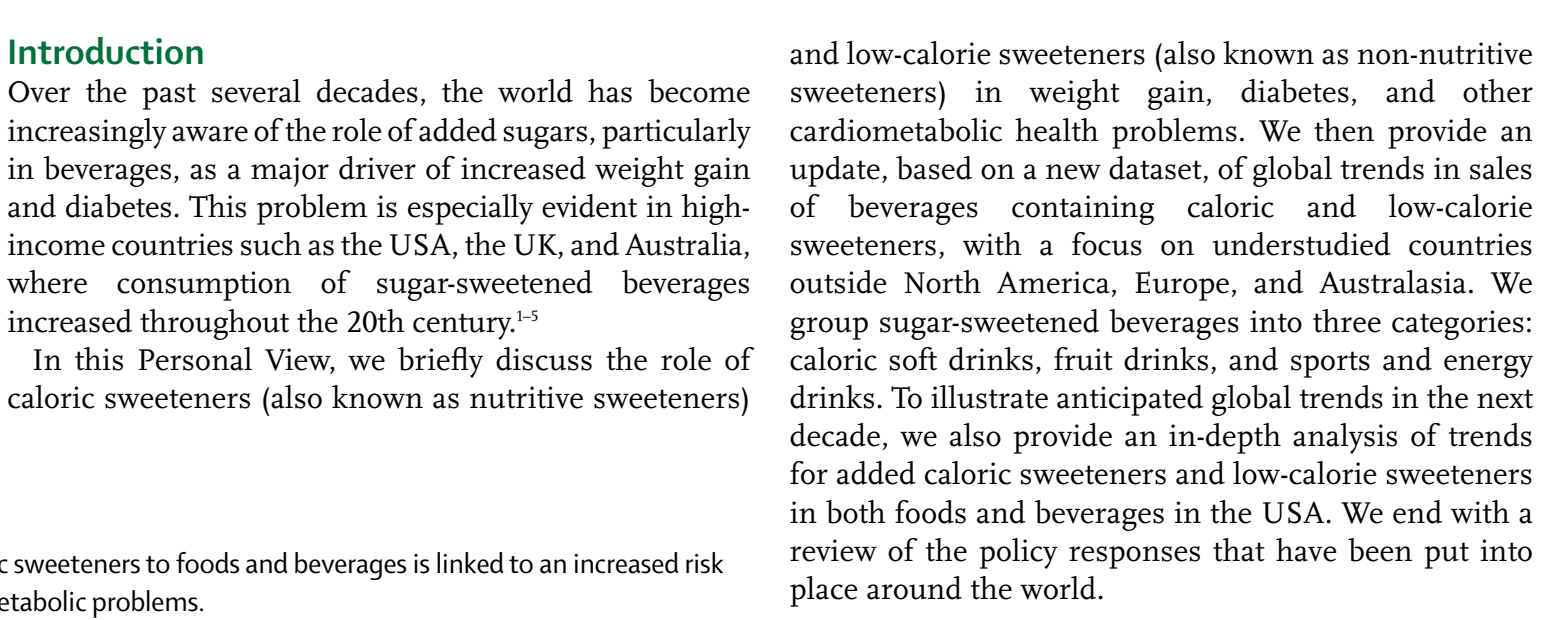

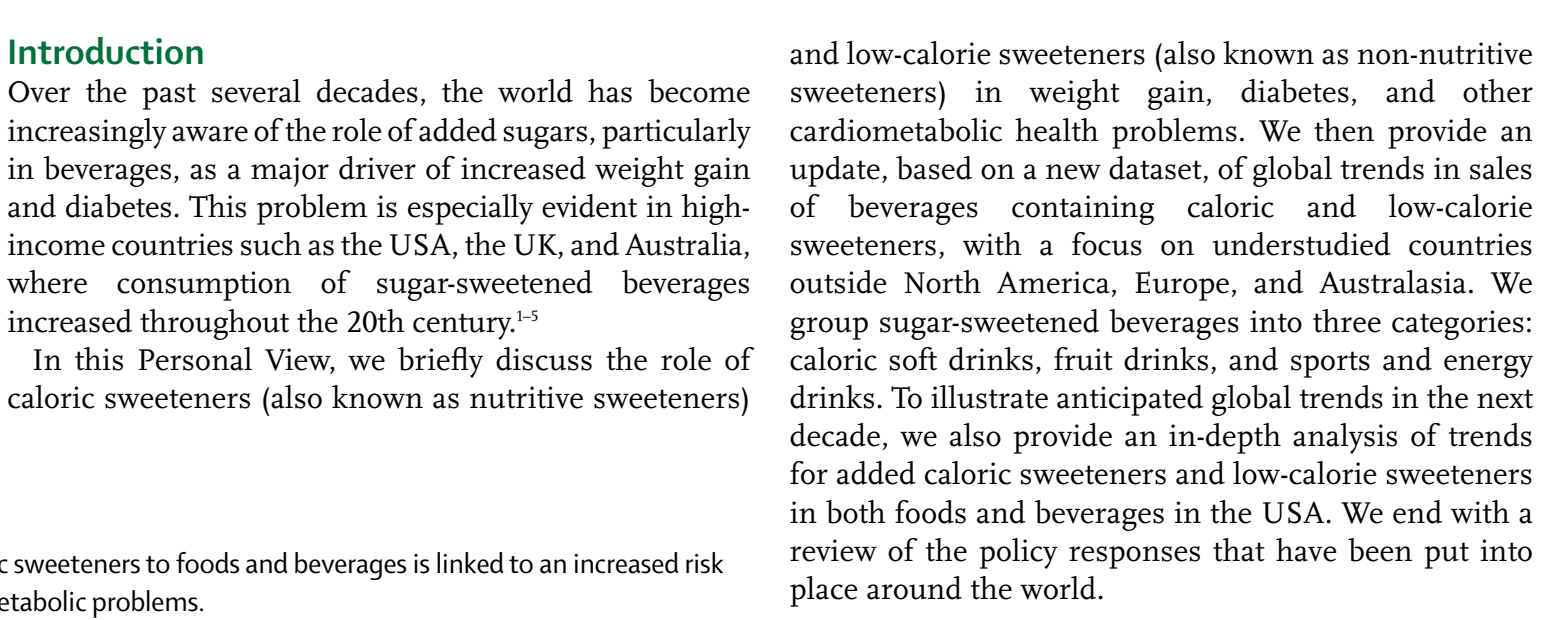

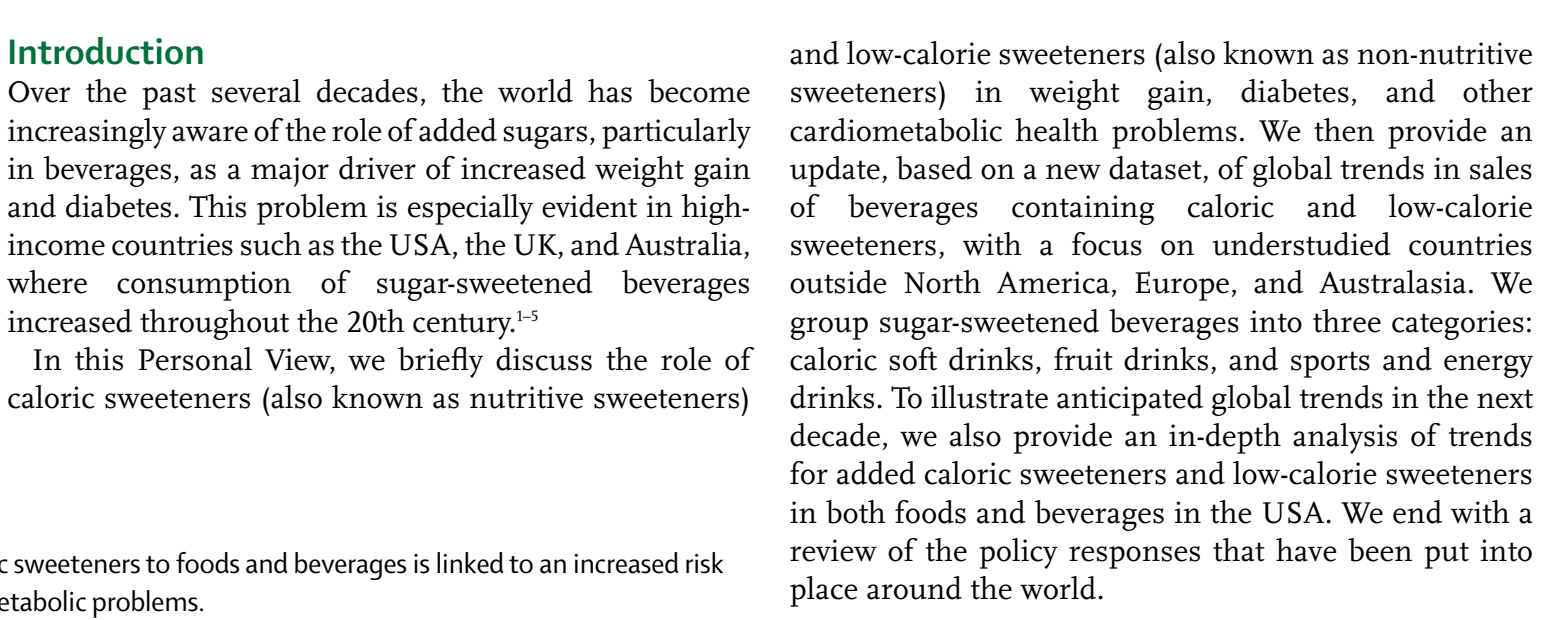

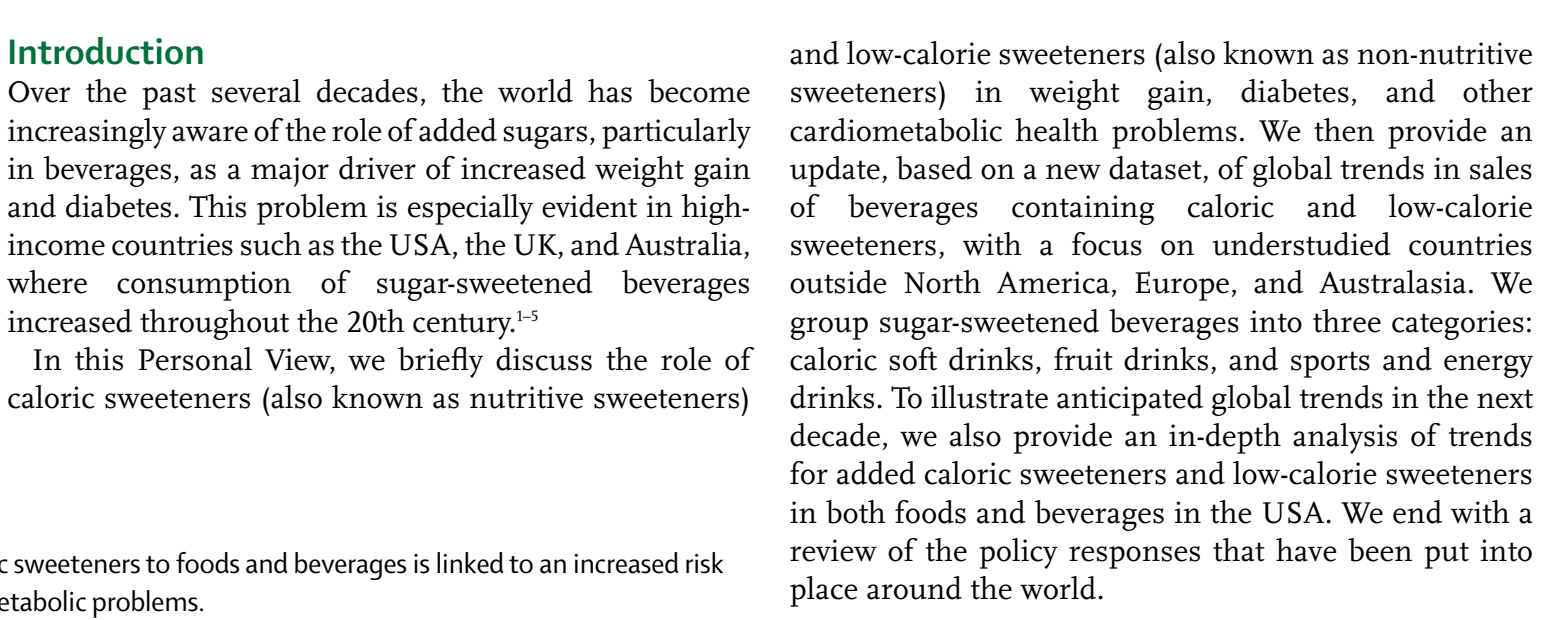

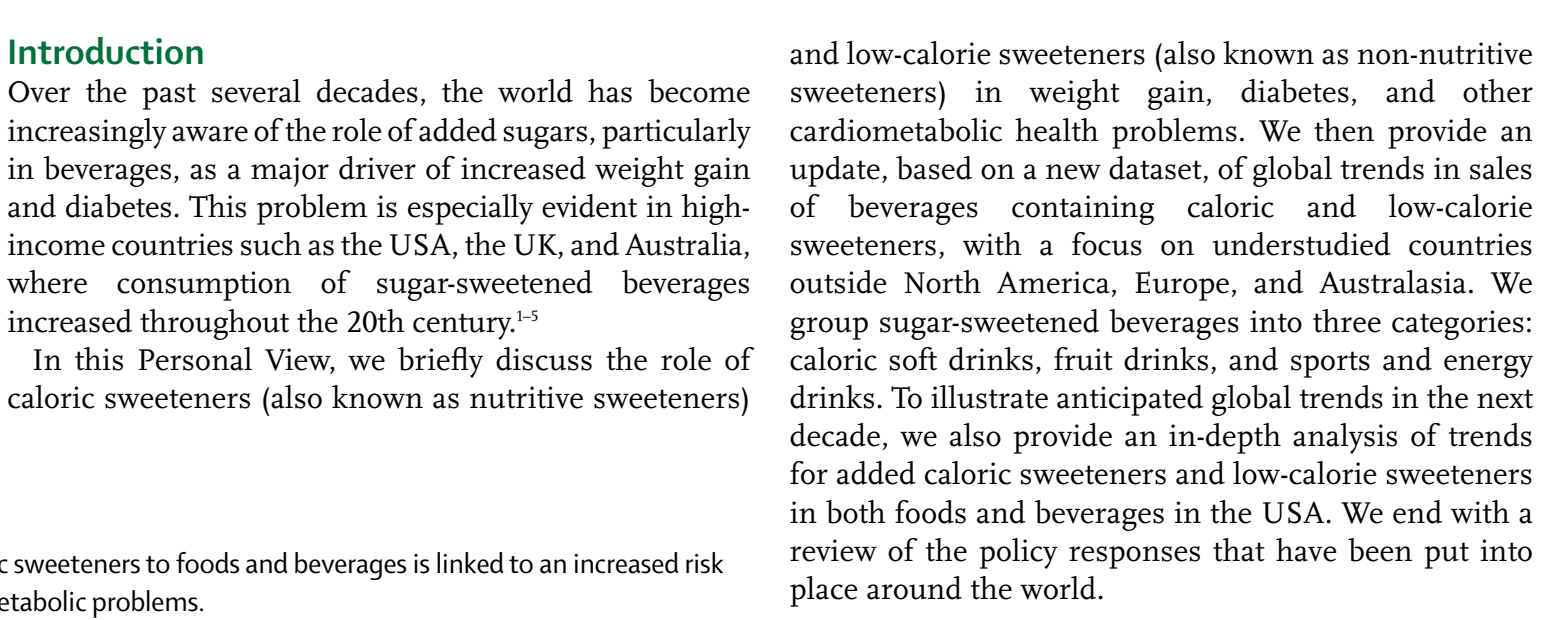

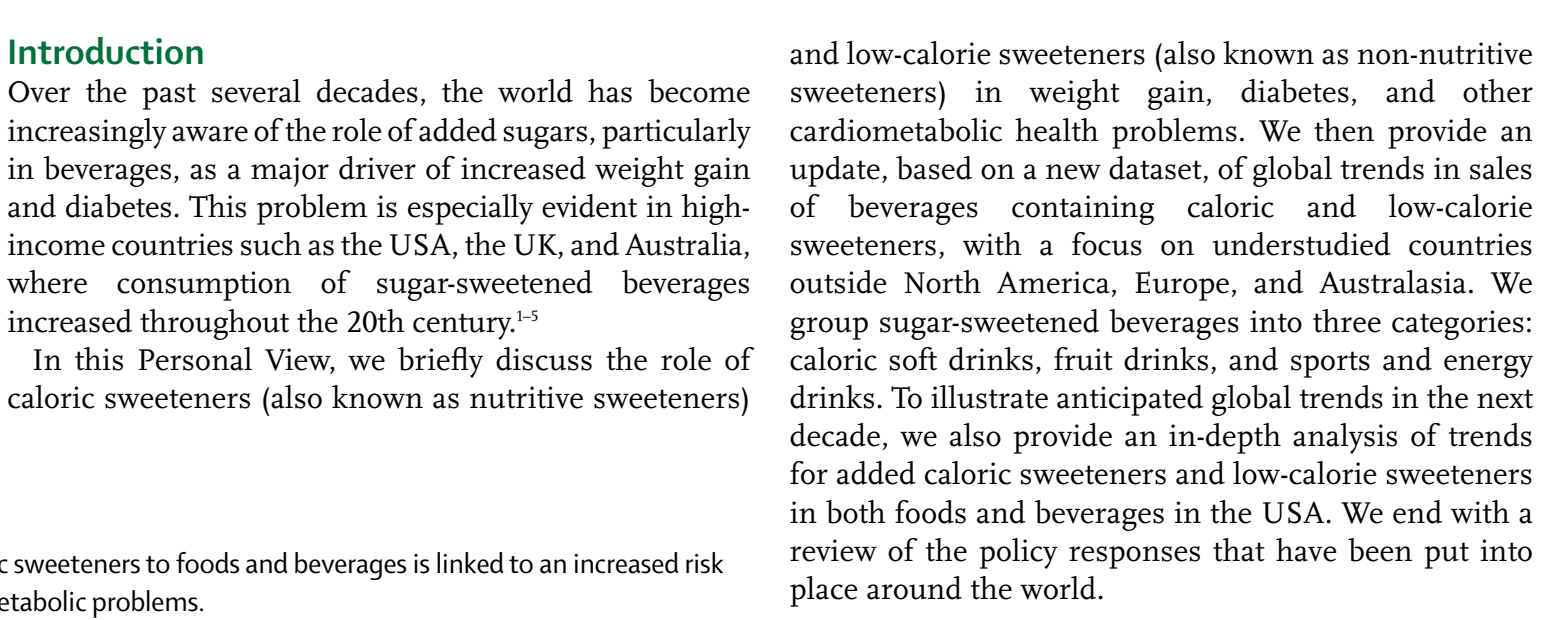

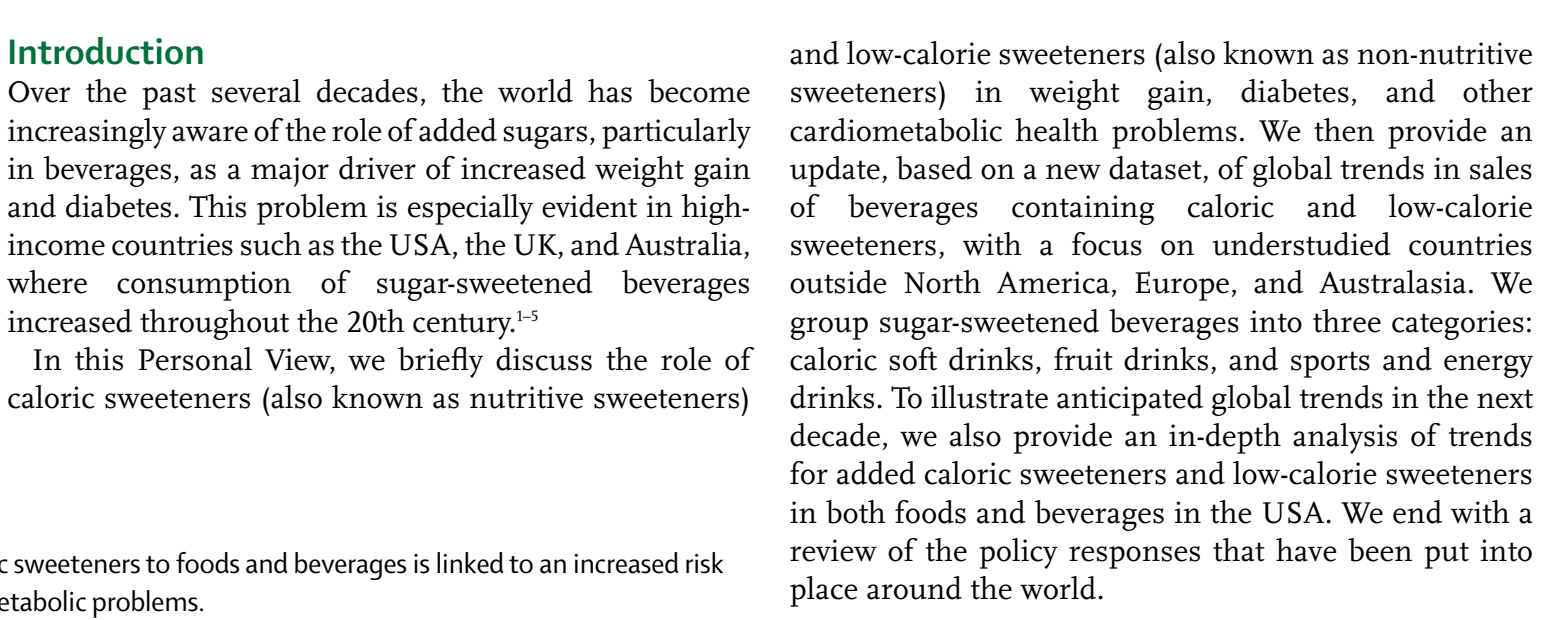

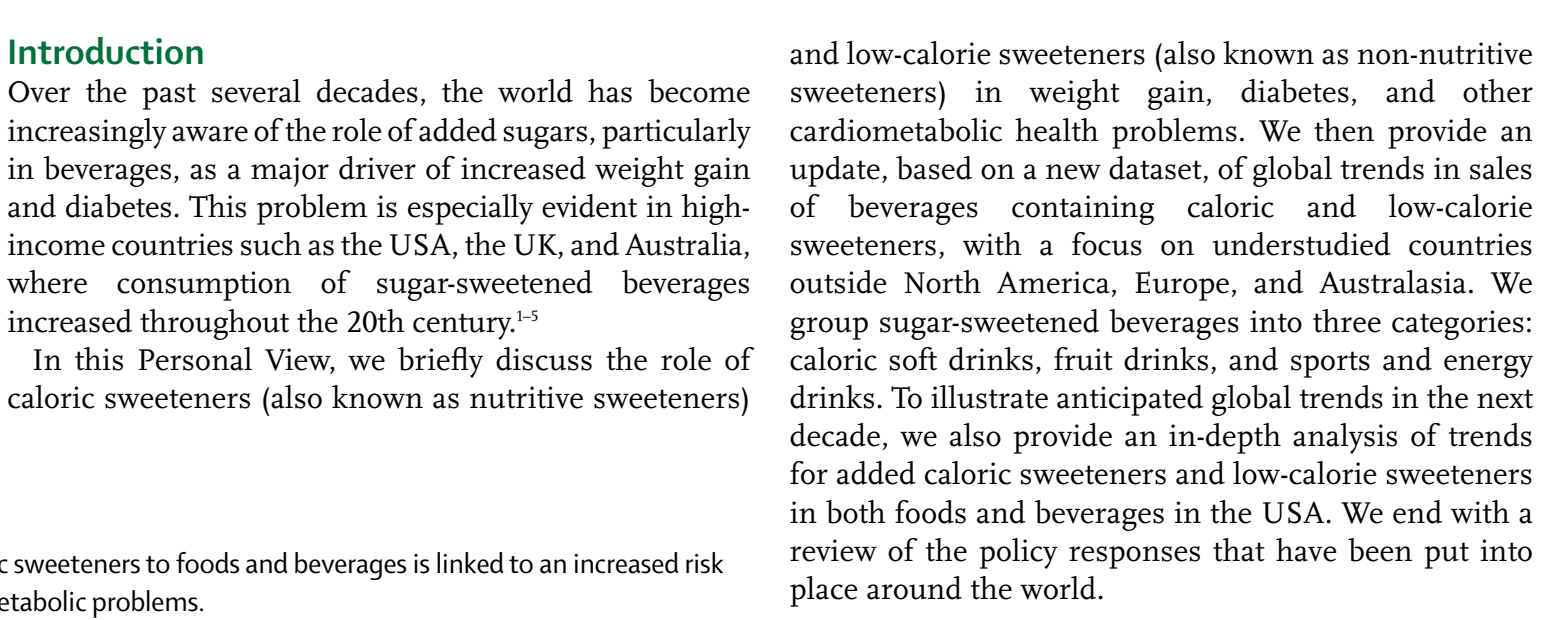

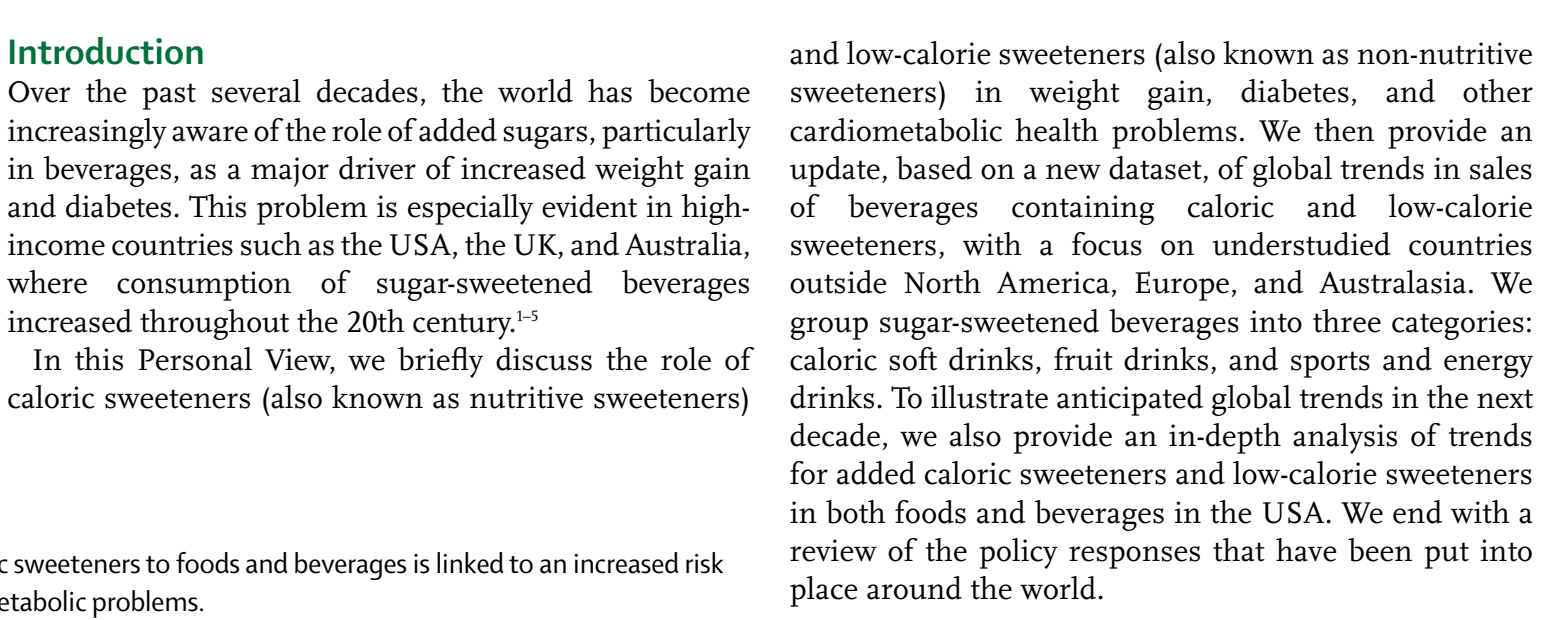

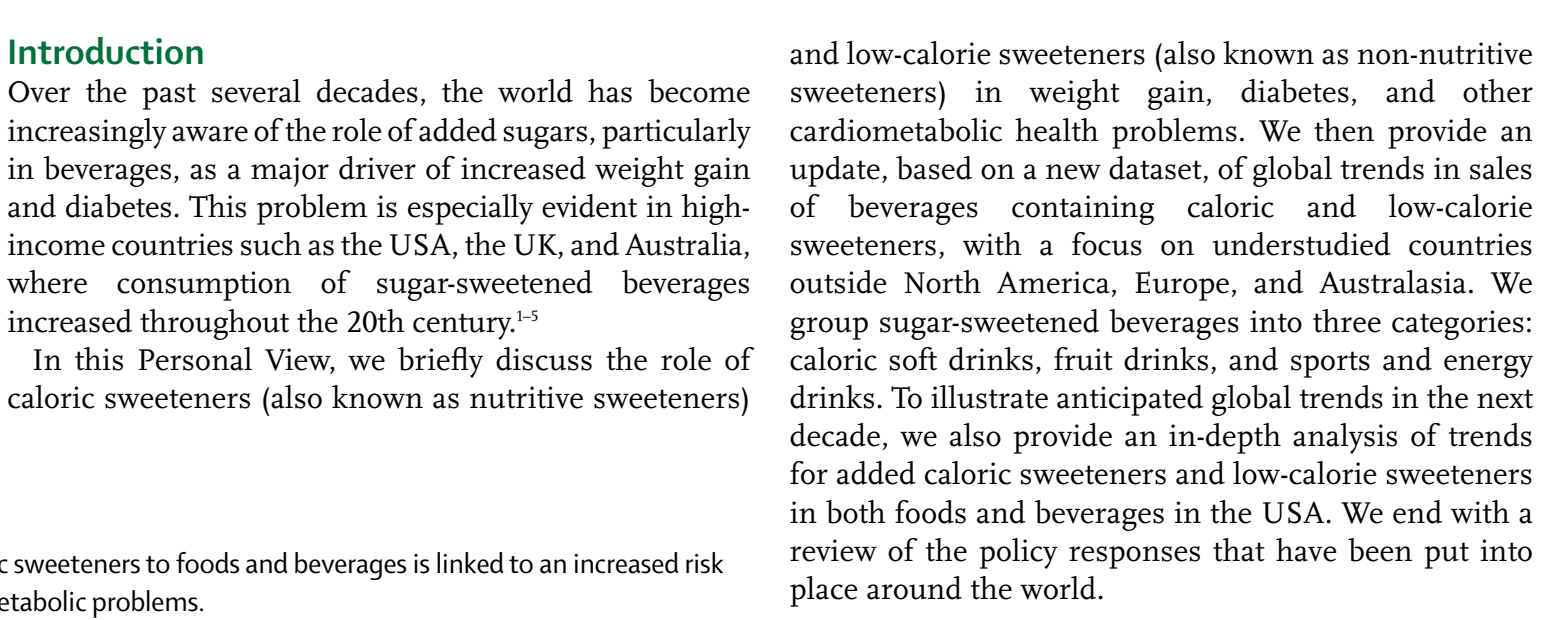

\section{Lancet Diabetes Endocrinol 2016; 4: 174-86 \\ Published Online December 1,2015 http://dx.doi.org/10.1016/ S2213-8587(15)00419-2 \\ See Online for podcast interview with Barry Popkin \\ School of Public Health, Carolina Population Center, University of North Carolina, \\ Chapel Hill, NC, USA (Prof B M Popkin PhD); Centre for Food Policy, School of Arts \& Social Sciences, City \\ University London, London, UK
(C Hawkes PhD)
Correspondence to:
Prof Barry M Popkin, School of
Public Health, Carolina
Population Center, University of
North Carolina, Chapel Hill,
NC 27516, USA
popkin@unc.edu (C Hawkes PhD) \\ Correspondence to: \\ University London, London, UK
(C Hawkes PhD)
Correspondence to:
Prof Barry M Popkin, School of
Public Health, Carolina
Population Center, University of
North Carolina, Chapel Hill,
NC 27516, USA
popkin@unc.edu \\ University London, London, UK
(C Hawkes PhD)
Correspondence to:
Prof Barry M Popkin, School of
Public Health, Carolina
Population Center, University of
North Carolina, Chapel Hill,
NC 27516, USA
popkin@unc.edu \\ University London, London, UK
(C Hawkes PhD)
Correspondence to:
Prof Barry M Popkin, School of
Public Health, Carolina
Population Center, University of
North Carolina, Chapel Hill,
NC 27516, USA
popkin@unc.edu \\ University London, London, UK
(C Hawkes PhD)
Correspondence to:
Prof Barry M Popkin, School of
Public Health, Carolina
Population Center, University of
North Carolina, Chapel Hill,
NC 27516, USA
popkin@unc.edu NC 27516, USA popkin@unc.edu} Evidence suggests that excessive intake of added sugars has adverse effects on cardiometabolic health, which is consistent
with many reviews and consensus reports from WHO and other unbiased sources. $74 \%$ of products in the US food contain caloric or low-calorie sweeteners, or both. Of all packaged foods and beverages purchased by a nationally $\%$ contain low-calorie sweeteners. We believe that in the absence of intervention, the rest of the world will move towards

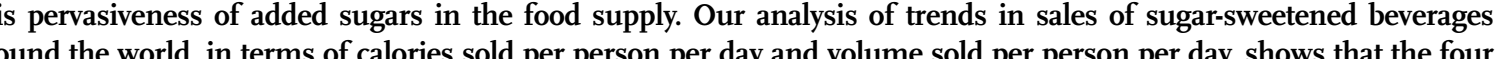
gions with the highest consumption are North America, Latin America, Australasia, and western Europe. The fastest
solute growth in sales of sugar-sweetened beverages by country in 2009-14 was seen in Chile. We believe that action is ugar-sweetened beverages in the past few years, including taxation (eg, in exico); reduction of their availability in schools; restrictions on marketing of sugary foods to children; public awareness
mpaigns; and positive and negative front-of-pack labelling. In our opinion, evidence of the effectiveness of these actions
ows that they are moving in the right direction, but governments should view them as a learning process and improve
eir design over time. A key challenge for policy makers and researchers is the absence of a consensus on the relation of
everages containing low-calorie sweeteners and fruit juices with cardiometabolic outcomes, since decisions about
hether these are healthy substitutes for sugar-sweetened beverages are an integral part of policy design. mico); reduction of their availability in schools; restrictions on marketing of sugary foods to children; public awareness
mpaigns; and positive and negative front-of-pack labelling. In our opinion, evidence of the effectiveness of these actions
ows that they are moving in the right direction, but governments should view them as a learning process and improve
ir design over time. A key challenge for policy makers and researchers is the absence of a consensus on the relation of
erages containing low-calorie sweeteners and fruit juices with cardiometabolic outcomes, since decisions about
ether these are healthy substitutes for sugar-sweetened beverages are an integral part of policy design. needed to tackle the high levels and continuing growth in sales of such beverages worldwide. Many governments have exico); reduction of their availability in schools; restrictions on marketing of sugary foods to children; public awareness
paigns; and positive and negative front-of-pack labelling. In our opinion, evidence of the effectiveness of these actions
ows that they are moving in the right direction, but governments should view them as a learning process and improve
verages containing low-calorie sweeteners and fruit juices with cardiometabolic outcomes, since decisions about
ether these are healthy substitutes for sugar-sweetened beverages are an integral part of policy design. paigns; and positive and negative front-of-pack labelling. In our opinion, evidence of the effectiveness of these actions
ws that they are moving in the right direction, but governments should view them as a learning process and improve
r design over time. A key challenge for policy makers and researchers is the absence of a consensus on the relation of
erages containing low-calorie sweeteners and fruit juices with cardiometabolic outcomes, since decisions about
ther these are healthy substitutes for sugar-sweetened beverages are an integral part of policy design.

(1)

1

(n)


seasonality of food and the need to drink water constantly to survive) have been identified..$^{13,14}$

Extensive meta-analyses show that the risk of weight gain and other cardiometabolic problems, especially diabetes, resulting from added sugars in beverages is substantial and that the risk increases with the amount consumed. ${ }^{415-21}$ The exceptions are studies funded by the sugar and beverage industries, which the authors of some reviews suggest are biased. ${ }^{22,23}$ Two important randomised controlled trials link intake of sugar-sweetened beverages in children and adolescents with excessive weight gain. ${ }^{24,25}$ In the past 3 years, two major meta-analyses of the effect of added sugars in food show that the risk of adverse cardiometabolic outcomes from caloric sweeteners in food is lower than the risk of caloric sweeteners in beverages. ${ }^{15,16}$ Nevertheless, WHO, the British Government dietary guidance committee, and many other countries and organisations recommend the reduction of addedsugar intake not only in beverages, but also in food. ${ }^{26-28}$ Partly on the basis of this risk, WHO published a revised guideline in 2015, in which it urged the reduction of added-sugar intake to less than $10 \%$ of total energy intake (strong recommendation), and a further reduction to below $5 \%$ of total energy intake (conditional recommendation). ${ }^{27}$ Several countries and medical associations (eg, Public Health England's Scientific Advisory Committee on Nutrition and the World Cancer Research Fund) have promoted the lower limit of 5\%.7,28

Although a consensus regarding the health effects of sugar-sweetened beverages has been reached, the cardiometabolic eff ects of $100 \%$ fruit juice need to be further studied. Some epidemiological studies suggest an adverse effect, ${ }^{11,12,29-35}$ whereas other reviews and studies identifi ed minimal evidence to support this conclusion. ${ }^{36}$ No randomised controlled trials have been done in either children or adults, which represents a major gap in research.

The eff ect of low-calorie sweeteners such as saccharin and aspartame (appendix p 8) on weight gain and diabetes risk is even more controversial than that of $100 \%$ fruit juice. Although careful reviews and randomised controlled trials did not identify evidence that low-calorie sweeteners increase energy intake, ${ }^{14,37}$ results from several longitudinal cohort studies implicate low-calorie sweeteners as a cause of increased weight, diabetes, and other adverse cardiometabolic outcomes. ${ }^{38-40}$ However, the investigators of these studies paid little attention to challenges presented by reverse causation and, potentially, effect modification by an existing unhealthy diet. Conclusions of adverse cardiometabolic eff ects of low-calorie sweeteners have been reversed in two cases when these issues were taken into account, ${ }^{41,42}$ and results from two randomised controlled trials did not show an adverse effect of beverages containing low-calorie sweeteners on cardiometabolic outcomes. ${ }^{43,44}$ However, no consensus has been reached on the role of low-calorie sweeteners in weight gain and diabetes risk; several ongoing randomised controlled trials should hopefully help to reach a consensus on the effects of low-calorie sweeteners on cardiometabolic health outcomes.

Another issue that has received renewed attention is the role of fructose. Fructose and glucose are the two main components of sugar (sucrose), and fructose levels can vary widely in different forms of sugar (roughly $45-55 \%$ of sugar in some high-fructose corn syrups and roughly $55-65 \%$ in some fruit juices). ${ }^{45,46}$ Glucose has important effects on obesity and other adverse health responses ${ }^{47}$ however, fructose, which is metabolised in the liver, seems to have unique adverse effects, such as increased liver fat, uric acid, visceral fat, muscle fat, and triglycerides. ${ }^{48-62}$

Almost all of this research into the health effects of beverages has been done in western Europe and North America, with the exceptions of longitudinal studies or randomised controlled trials in Singapore, ${ }^{33,63}$ Japan, $^{64}$ and Mexico. ${ }^{65}$ Research in the USA shows that the relations between BMI and intake of sugar-sweetened beverages might be stronger in Hispanic ${ }^{66-69}$ and Asian individuals than in white individuals, suggesting the importance of doing further research in other countriesespecially in India and China, since the dearth of studies in these two countries represents a major gap in research.

In summary, existing evidence shows that increased sugar intake amplifies the risk of weight gain, diabetes, and many other cardiometabolic problems. Many beverages containing caloric sweeteners have adverse health effects, but further research is needed to investigate the health effects of beverages containing low-calorie sweeteners and $100 \%$ fruit juices.

\section{Caloric and low-calorie sweeteners in the US food supply}

The USA has one of the world's most complex food supplies in terms of the number of products with unique ingredients; however, our research and that of others show that this modern supermarket-based system is growing rapidly in most low-income and middle-income countries. Thus, study of the US food supply can help to illustrate global trends-eg, the extent to which sweeteners are added in packaged foods and beverages. ${ }^{70-74}$ We analysed data from the Nielsen Homescan Services nationally representative sample of US households, which are based on scans from all barcoded food sold in 2000, 2006, and 2013 with "unique formulations of ingredients" (1.2 million foods in the USA between 2000 and 2013; appendix pp 1-2). We linked food sales to nutrition fact panels, ingredients, and components of each of the listed ingredients to ascertain the extent of the use of caloric sweeteners and low-calorie sweeteners in packaged foods and beverages. Published work shows that a large proportion of US foods and beverages include the natural sweetener, fruit juice concentrate. ${ }^{75} \mathrm{We}$ included as an added sugar any beverage with both fruit 

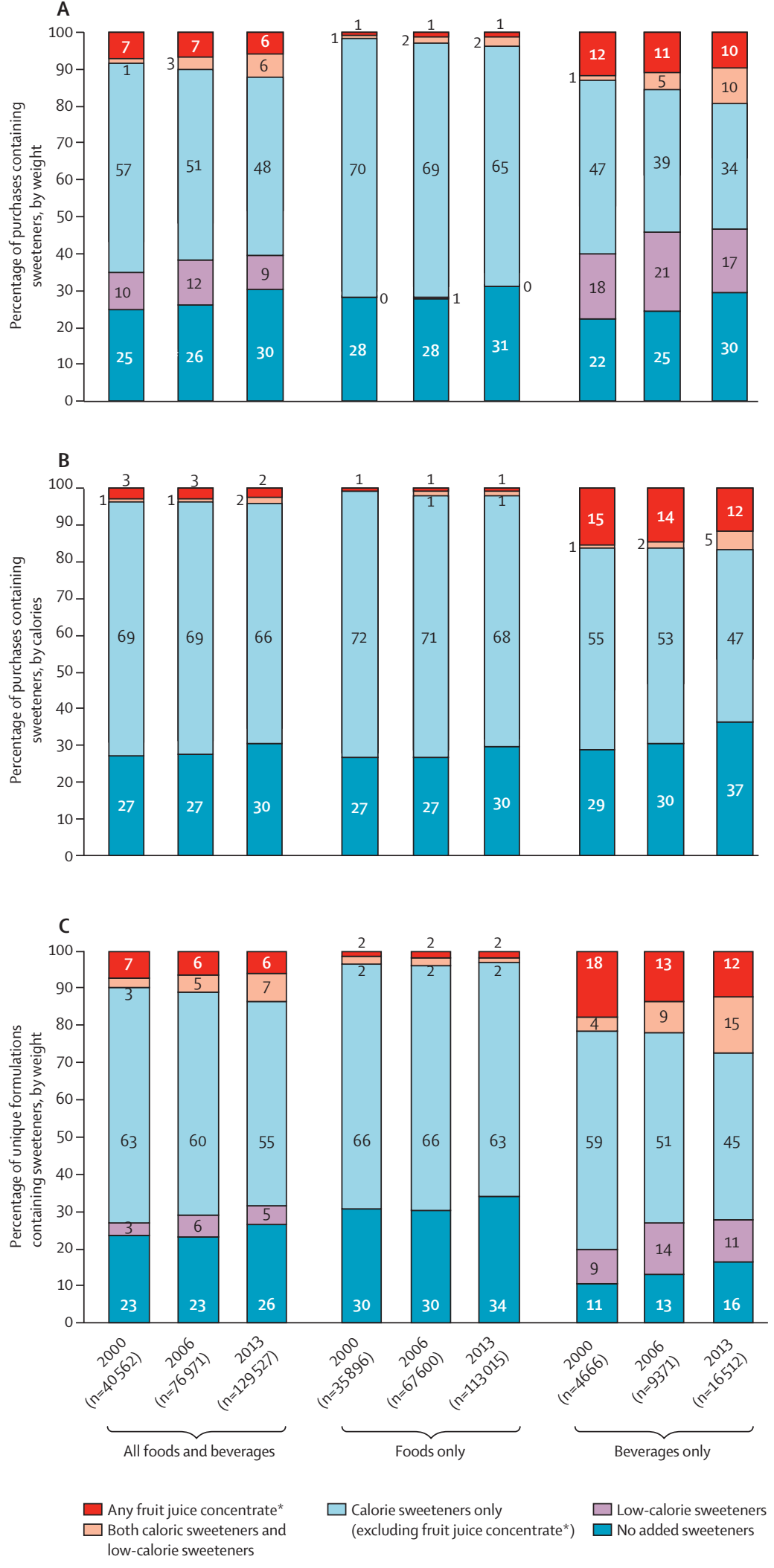

juice concentrate and water as a caloric sweetener rather than as $100 \%$ fruit juice (see appendix pp 5-8 for all the types of sweeteners included in our search). In many foods and beverages, fruit juice concentrate is not shown as a stand-alone ingredient on the label, so we also searched the components of the ingredients on the nutrition fact panel for various juice concentrates (appendix p 6). We excluded sugar alcohols, as does the US Food and Drug Administration, since their caloric effect is minimal; we also excluded two new, rarely used low-calorie sweeteners, allulose and tagatose.

Our analysis shows a significant increase in the proportion (by weight) of purchased products, especially beverages, with both caloric sweeteners and low-calorie sweeteners, and also a significant increase in that of purchases, especially beverages, with no added sweeteners between 2000 and 2013 (figure 1A). In 2013 , $30 \%$ of all food calories and $37 \%$ of all beverage calories purchased were in products that did not have added sweeteners (figure 1B), which lends support to earlier work showing that intake of total added sugars in the USA has declined since 2000 and that much of this shift is caused by a reduction in the consumption of caloric beverages. ${ }^{76,7} 68 \%$ of packaged foods and beverages available in the USA contain caloric sweeteners, $74 \%$ include both caloric and low-calorie sweeteners, and 5\% have only low-calorie sweeteners (figure 1C). The proportion (by weight) of purchases containing fruit juice concentrate remained similar between 2000 and 2013 (figure 1A). Although the number of foods sweetened with fruit juice concentrate remained the same, the number of beverages with fruit juice concentrate declined substantially (figure 1C), as did the proportion of beverages bought, in terms of volume and calories, although to a lesser extent.

\section{Trends in beverage sales}

We used data for global trends in beverage sales from the Euromonitor Passport International database, ${ }^{78,79}$ which has been used in other studies of sugar-sweetened beverages.$^{80}$ Our definition of sugar-sweetened beverages included caloric soft drinks (carbonated and noncarbonated), fruit drinks (sweetened beverages of diluted fruit juice and often other caloric sweeteners and flavourings), and several fast-growing categoriesnamely, energy drinks, sports drinks, and sugarsweetened (often flavoured) waters, which we combined in our analysis as sports and energy drinks. Our analysis

Figure 1: Food and beverage products containing sweeteners in the US food supply

Percentage of purchases of uniquely formulated consumer packaged goods containing sweeteners, $(\mathrm{A})$ by weight $(\mathrm{g})$ and $(\mathrm{B})$ by calories ( $\mathrm{kcal}$ ), weighted to be nationally representative. (C) Percentage of unique formulations containing sweeteners, by weight (g). Calculations were partly based on data reported by Nielsen through its Homescan Services for the food and beverage categories. *Fruit juice concentrate includes products in which water is present as an ingredient, but excludes lemon or lime and when reconstituted. 
adds to earlier studies on sales volumes, which had little disaggregation, since ours is the first to include data for trends in caloric levels in sugar-sweetened beverages (appendix pp 2-4). ${ }^{79}$ Euromonitor International allowed our research team to beta-test and use these new caloric data to analyse the breakdown of beverages in more detail than is traditionally provided by Euromonitor online. We combined sales for off-trade volume (ie, supermarkets and retailers) and on-trade volume (ie, restaurants and cafeterias) reported in volume $(\mathrm{mL})$ sold per person per day. Caloric data were available only for off-trade sales, and regional averages were weighted by the population of each country in that area.

We compared our results with intake levels of sugarsweetened beverages from national nutritional surveys and several large-scale studies of such intake across the world (appendix pp 2-3). ${ }^{19,21}$ Some limitations of our dataset were that many small local bottlers were likely to have been omitted, and that consumption for a few countries - notably, Colombia—seemed much lower than that in national nutrition surveys and regional dietary intake patterns from 24-h recall studies. Moreover, the data were of average purchases for the country, included waste, and did not include information about per-person consumption of key age groups that are more likely to consume sugar-sweetened beverages (ie, people aged 10-35 years), as was done in a cross-sectional presentation of global dietary data. ${ }^{21}$ However, the data do seem to be accurate with respect to the identification of trends in both volume and calories of sugar-sweetened beverages sold, since the results align closely with our own findings on trends in purchases and dietary intake of sugar-sweetened beverages in the USA ${ }^{76}$ and Mexico. ${ }^{77}$ The trends from our analysis (figures 2-5; appendix pp 2-3) also accord with findings from two recent reports. ${ }^{19,80}$ Singh and colleagues' study $^{19}$ of cross-sectional dietary intake data of sugarsweetened beverages from individual surveys showed that the Caribbean region that was not represented by Euromonitor caloric intake data consumed greater volumes of sugar-sweetened beverages than did other regions. Basu and colleagues' ecological analysis of Euromonitor data ${ }^{80}$ showed a strong association between sales of such beverages at the country level and the prevalence of diabetes.

North America and Latin America are the largest consumers of sugar-sweetened beverages, with sales in Asia Pacific substantially lower (figure 2A). In 2009-14, sales fell in North America, Australasia, and western Europe, but increased in all other regions (figure 2B; appendix pp 14, 16, 18-22, 24). Important differences
For Euromonitor see http:// www.euromonitor.com/
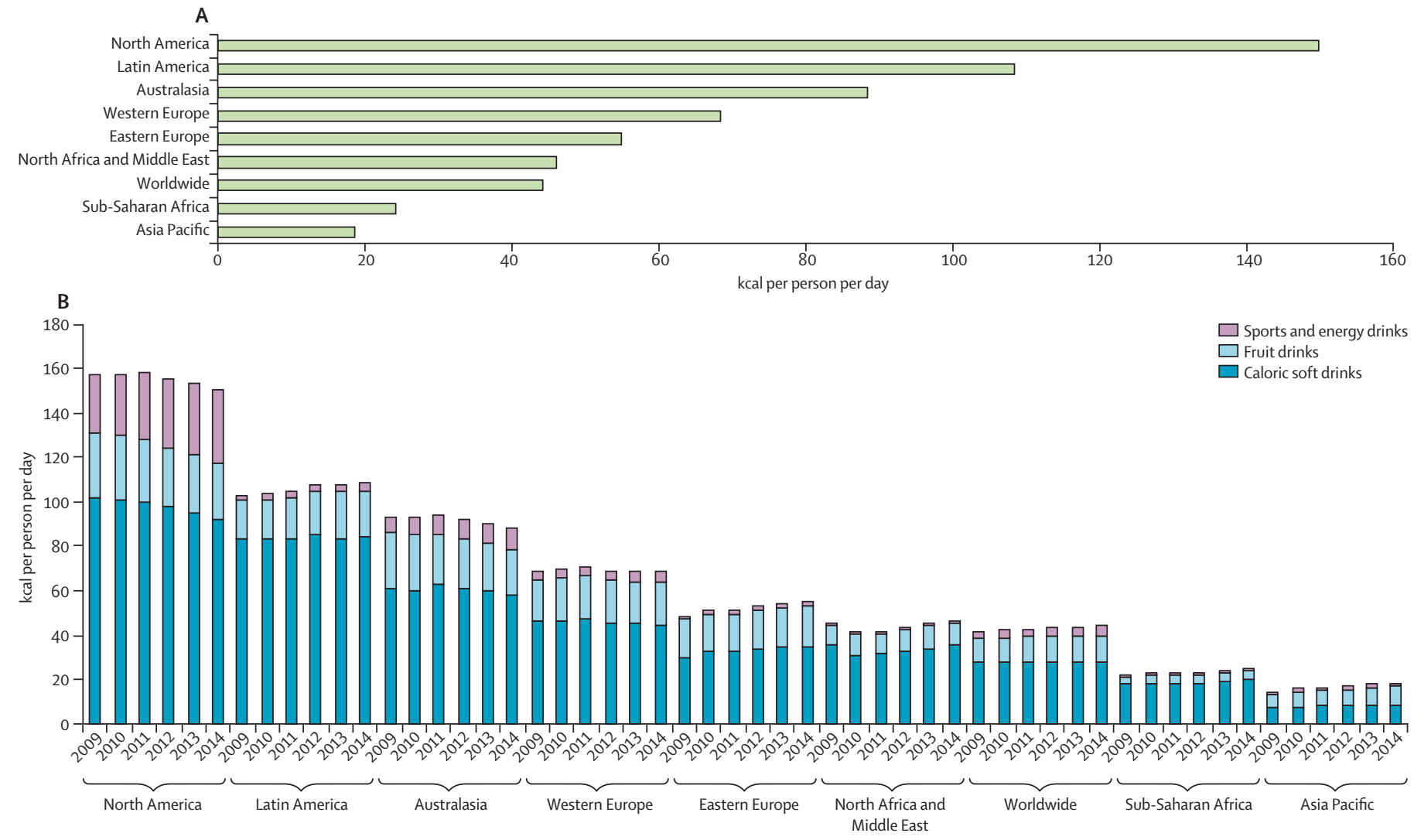

Figure 2: Sales of sugar-sweetened beverages by region in 2014 (A) and trend in sales, 2009-14 (B) 
between regions are seen in the types of beverages sold. Although caloric soft drinks are a dominant contributor to daily calories sold per person in most regions, fruit

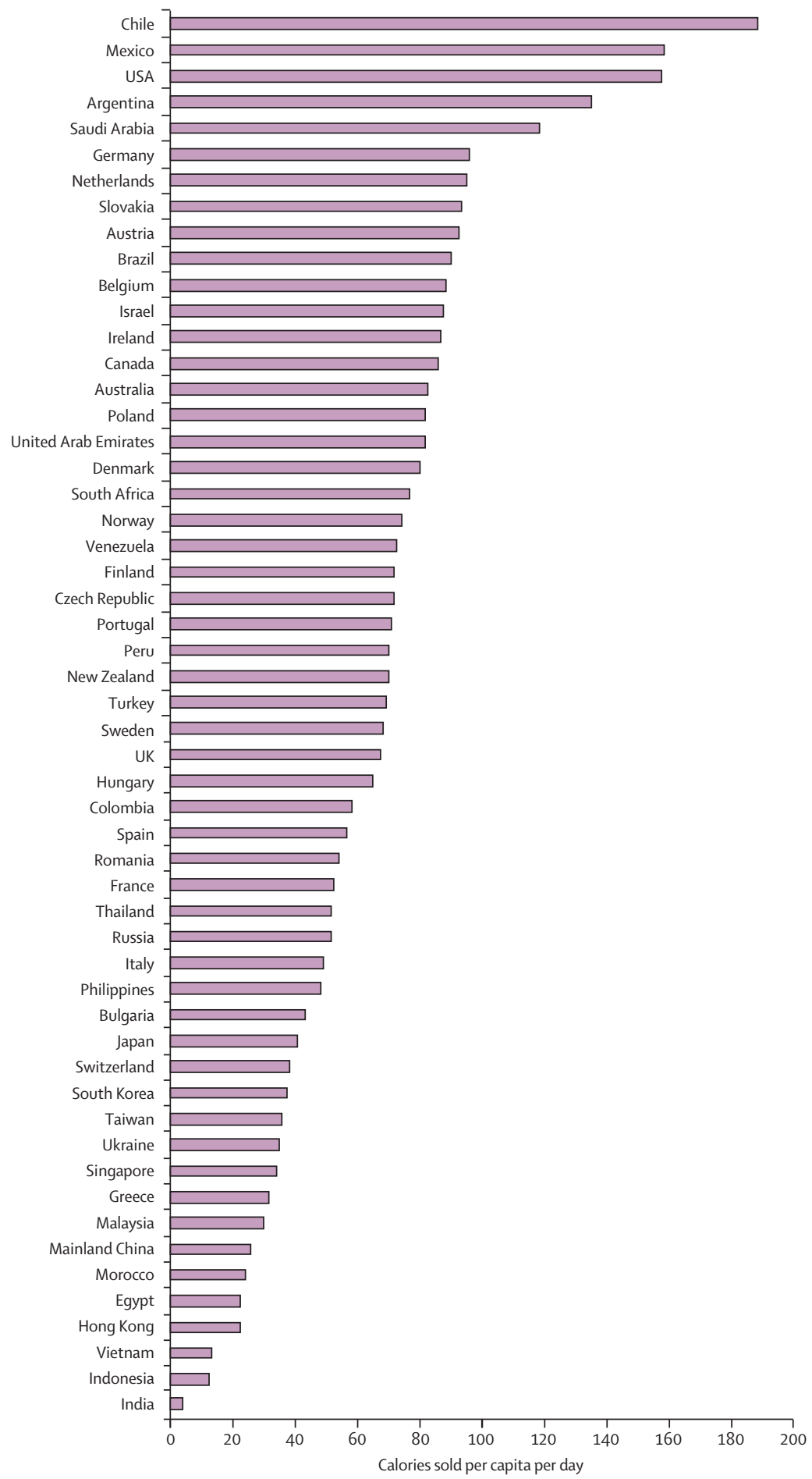

Figure 3: Sales of caloric beverages in 2014

Data from Euromonitor Passport International, which were obtained from nutrition fact panels and websites of sugar-sweetened beverage companies. drinks contribute equally in Asia Pacific. Sales of caloric soft drinks remained fairly stable in Latin America, while sales of fruit drinks increased. In North America, sales of caloric soft drinks declined substantially, but sales of sports drinks increased significantly. Such an increase in sales of sports drinks was also seen in Australasia, although sales of soft drinks remained stable, with the overall decline being explained mainly by the decrease in fruit drinks sold. Worldwide, sales of caloric soft drinks remained fairly unchanged, whereas sales of fruit drinks and energy drinks increased.

Enormous heterogeneity exists in sales volumes and trends within regions. Three of the six countries with the highest per-person daily calories sold from sugarsweetened beverages are in Latin America, with Chile being the highest, followed by Mexico in second place and Argentina in fourth place (figure 3; appendix p 10). The USA and Saudi Arabia are also in the top six. This situation is different from that in 2000, when the USA was the largest consumer, before the substantial decline in consumption of sugar-sweetened beverages. National trends in different types of sugar-sweetened beverages reflect regional trends-eg, China shows a large growth in fruit drinks consumed (appendix p 15).

Changes in sales of sugar-sweetened beverages also differ between countries in the same region (figure 4)eg, Chile and Mexico, two countries where the health effects of sugar-sweetened beverages have received extensive media and political attention. The data in our analysis show that some countries, such as China, Thailand, Brazil, and Chile, are facing growth in sales of sugar-sweetened beverages, whereas others such as the UK, Mexico, and the USA are seeing declines. In the case of Mexico, this decline occurred before the sugar tax was instituted, possibly because of the much more visible and well-funded media campaign linking sugarsweetened beverages with diabetes (which is called "urino con azucar" in Mexico). By contrast, much of the Chilean effort was aimed at direct discussions with congressional representatives led by several active senators ${ }^{81}$ Decline in overall sales was also apparent in the USA, despite increases in sales of sports and energy drinks.

The caloric trends essentially mimic the 2000-14 trends in sales in volume, with a few exceptions (appendix pp 14-24). The USA is one example in which the two trends diverge, since sales have shifted to beverages with low caloric content, often by replacing caloric sweeteners with low-calorie sweeteners (figures 1-3). Asia, including China, is characterised by the increasing consumption of fruit drinks. China has seen a remarkable increase in sales of sugar-sweetened beverages since 2000, but the change is smaller than that in Chile (figure 4). Both longterm and short-term data show that a major focus of global beverage companies is to promote consumption in less saturated, emerging markets (eg, China [appendix $\mathrm{p}$ 15], Thailand, and the Philippines) beyond the 


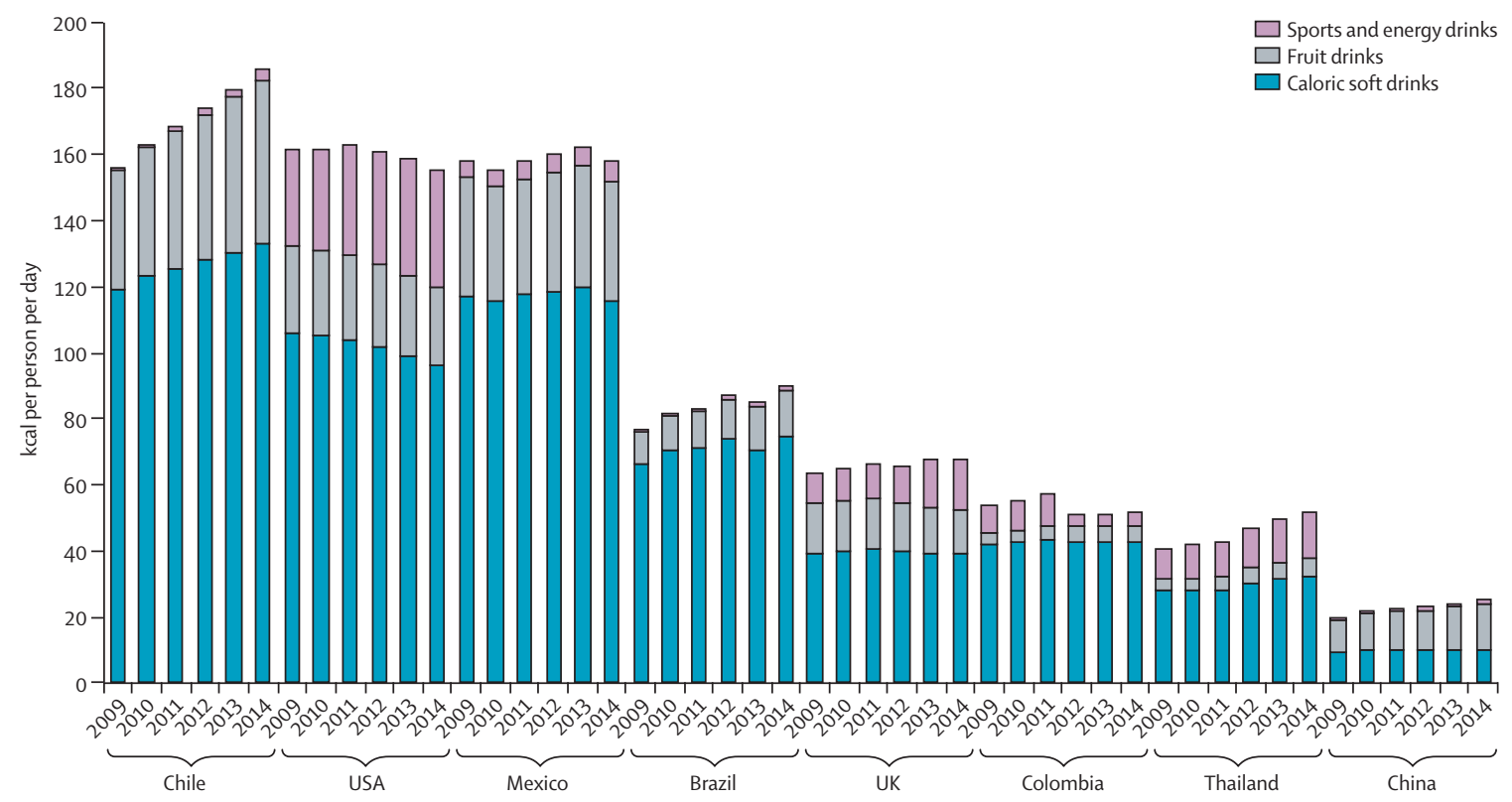

Figure 4: Sales of beverages in 2009-14 in selected countries

Data from Euromonitor Passport International, which were obtained from nutrition fact panels and websites of sugar-sweetened beverage companies. kcal=kilocalories
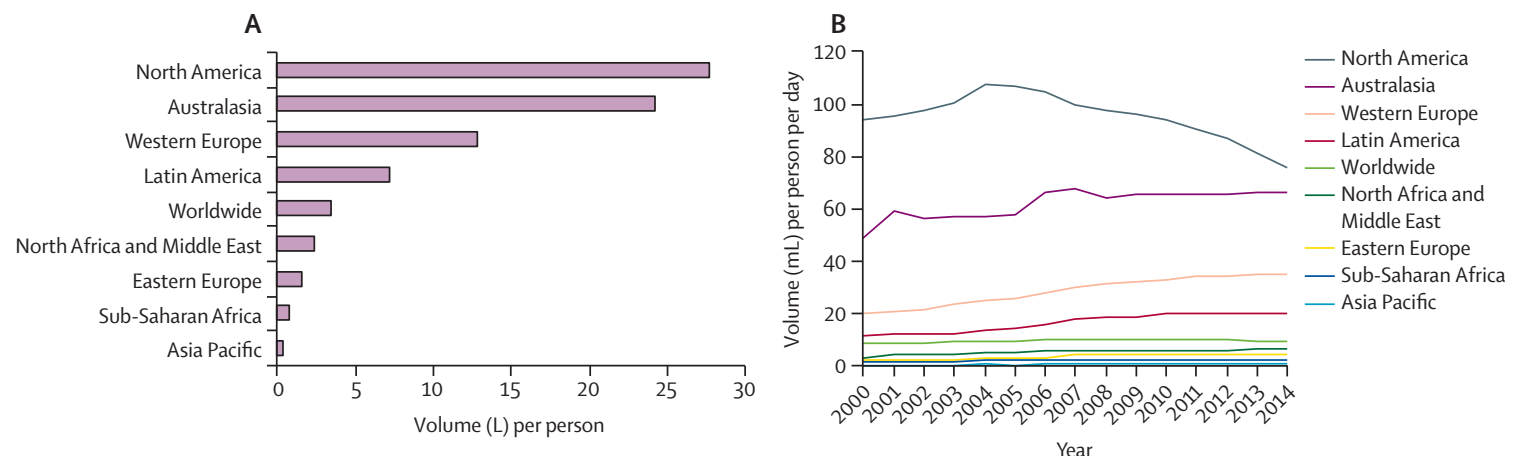

Figure 5: Sales of diet beverages with only low-calorie sweeteners in 2014 (A) and trends in 2000-14 (B)

established markets in high-income countries such as the USA, Australia, and the UK. ${ }^{82}$ Aside from North America, Australasia, and western Europe, few regions consume many beverages containing low-calorie sweeteners; North America, Australia, and New Zealand consume twice as many such beverages as do other regions (fi gure 5; appendix p 12).

\section{Policy responses}

\section{Global overview}

In view of the adverse health effects associated with the widespread consumption of sugar-sweetened beverages, many national governments have taken action to reduce consumption. ${ }^{26,83}$ We identified such policies from the World Cancer Research Fund (WCRF) International NOURISHING database. ${ }^{84,85}$ Actions led by the private sector were not included. This database does not represent a comprehensive global survey, so our review of existing policy actions was selective. We identified the most common actions, the number of actions in lowincome and middle-income countries, and how policy makers have dealt with the scientific uncertainty about potential substitutes of sugar-sweetened beverages. We reviewed the effects of some of these policies, on the basis of evaluation of actions taken at the local level (eg, in school districts) and in research settings. Aside from that of the Mexican tax on sugar-sweetened beverages, few national-level and statistically rigorous studies have been done in low-income and middle-income countries. We also look at trends in consumption of sugarsweetened beverages in countries that have implemented health-related food taxes. 


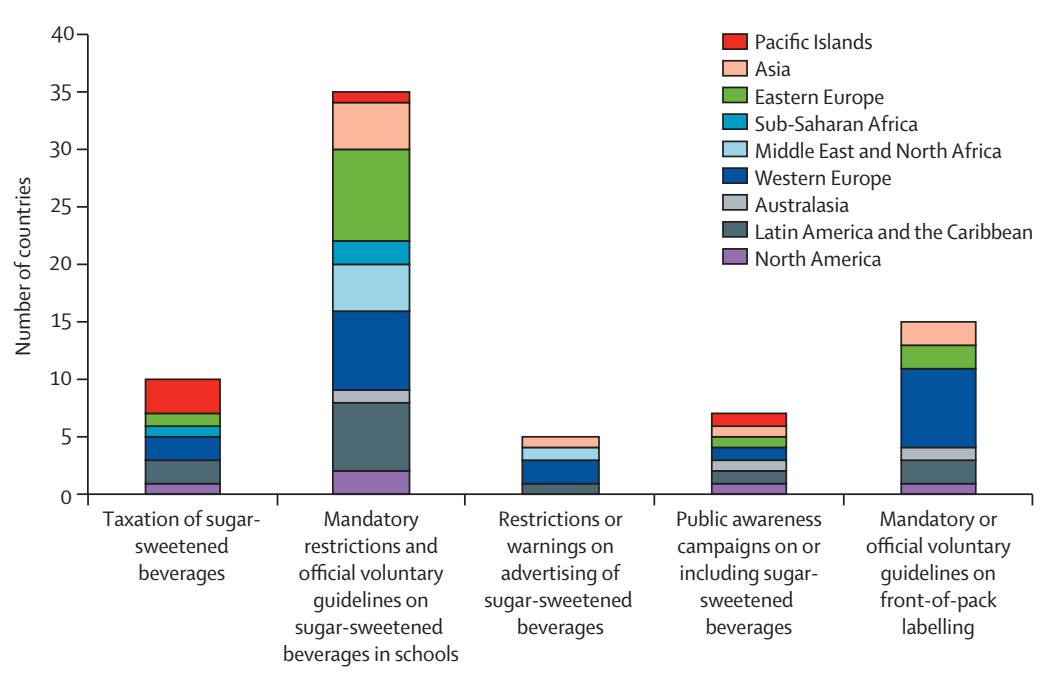

Figure 6: Number of countries that have implemented policies on sugar-sweetened beverages (including at the sub-national level)

Data from World Cancer Research Fund International NOURISHING database.

Many countries have started to attempt to reduce consumption of sugar-sweetened beverages, and the most common actions implemented so far include taxation, reduction of availability in schools, restrictions on marketing to children, public awareness campaigns, and front-of-pack labelling. Most of these actions are not specific to sugar-sweetened beverages, but do include them. Although we identified 72 policy actions that have been implemented in 49 countries, covering all world regions (figure 6 ),${ }^{85}$ none of these actions is implemented in low-income countries. Only one (2\%) lower-middleincome country (Samoa) and 16 (33\%) upper-middleincome countries have enacted such actions; most of the actions are implemented in high-income countries, where consumption is generally highest but more likely to be stabilising. This finding suggests that more policy actions are needed beyond high-income countries where rates of consumption are rising.

\section{Taxation}

The most notable policy development in the past 2 years is the increasing governmental interest in taxation of sugarsweetened beverages or foods with added sugar, or both. As of May, 2015, national-level taxes have been implemented in five countries in Latin America and Europe (Chile, Mexico, Finland, Hungary, and France), four small island states (Samoa, Mauritius, French Polynesia, and Tonga), one city (Berkeley, CA, USA), and one Native American reservation (Navajo Nation in the USA). So far, taxation rates have mostly been lower than the level of $20 \%$ or more recommended by scholars ${ }^{86}$-eg, 2\% in Navajo Nation (implemented in April, 2015), 8\% in Chile (January, 2015), 10\% in Mexico (January, 2014) and France (January, 2012), and higher (around 15-30\%) in French Polynesia and other western Pacific Islands. ${ }^{87}$
The highest rate is the $12-25 \%$ tax (depending on the size of the container) in Berkeley. In several countries, the tax covers more than sugar-sweetened beverages. In Hungary, for example, the tax (adopted in 2012) applies to the sugar, caffeine, and salt content of various categories of ready-toeat foods and drinks, including energy drinks, which are widely consumed by young people. In Mexico, the tax on sugar-sweetened beverages is combined with a roughly $8 \%$ tax on so-called non-essential foods that are high in added sugar, sodium, or unhealthy saturated fats.

What has been the effect of these taxes? In Hungary, an econometric analysis of broad food and beverage categories from household expenditure data showed a $3.4 \%$ decrease in the purchase of processed foods and a $1 \cdot 1 \%$ increase in the purchase of unprocessed food after the tax was introduced; 88 other initial reports suggested a much larger decline (27\%) in sales of taxed foods and extensive reformulation of food products. ${ }^{89}$ This decline is also seen in the Euromonitor data (figure 7). In France, the tax led to a roughly $5 \%$ price increase, with Euromonitor data showing a small effect on sales (figure 7) and WHO also reporting a 3.3\% reduction in sales. ${ }^{89}$ In Chile, a continued increase in consumption was seen up to Jan 1, 2015, when the tax was implemented. The Chilean evaluation will be initiated, with similar data and methods as those used in the Mexican evaluation, in 2016 by the Global Food Research Program of the University of North Carolina and the Institute of Nutrition and Food Technology, University of Chile.

A joint team from the University of North Carolina and the Mexican National Institute of Public Health is investigating the long-term effects of the taxes in Mexico on food and beverage purchase patterns." Their evaluation of the tax on sugar-sweetened beverages showed an average decline of $6 \%$ in purchases of taxed beverages in 2014, compared with pre-tax levels. This difference became more pronounced over 2014, and the reduction compared with pre-tax trends reached $12 \%$ by December, 2014. All socioeconomic groups purchased fewer taxed beverages. Reductions were higher in households with low socioeconomic status, with a $9 \%$ average decline in 2014 and up to a 17\% decline by December, 2014. The first year of this tax has therefore already led to the expected significant declines in purchases of sugar-sweetened beverages and increases in purchases of bottled water; in theory, the longer-term effect could be even greater if taxes affect people's longterm preferences and move their habits away from the consumption of sugar-sweetened beverages. ${ }^{90-93}$ However, this assumption does not account for changes in industry behaviour in response to taxation policies, so the longterm effects are difficult to predict.

\section{Restrictions of availability in schools}

A major focus of government actions around the world has been to improve the quality of foods available in schools. ${ }^{94}$ Although the policies vary substantially from 


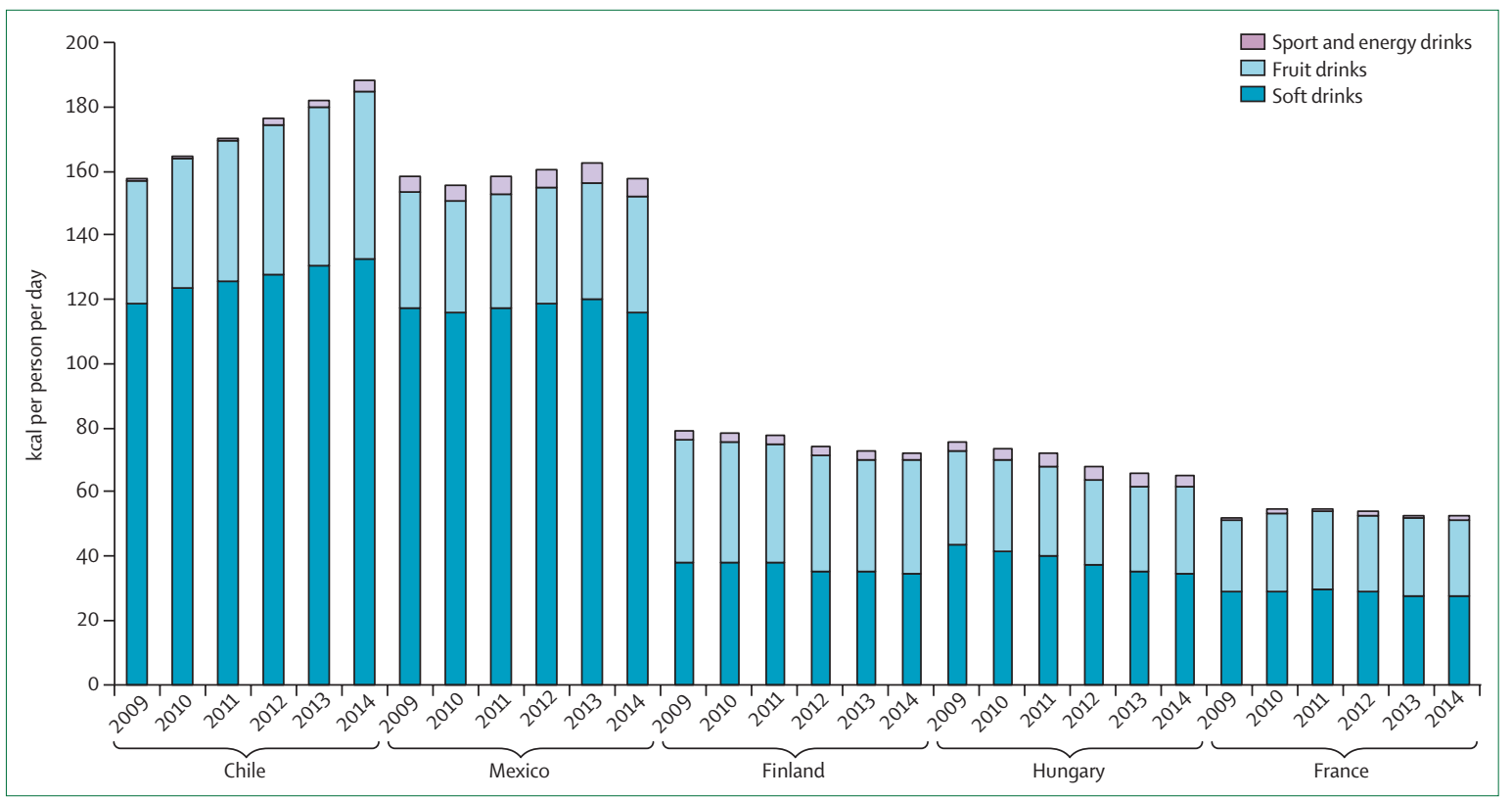

Figure 7: Sales of caloric beverages in countries with sugar taxes, 2009-14

Data from Euromonitor Passport International, which were obtained from nutrition fact panels and websites of sugar-sweetened beverage companies. kcal=kilocalories.

place to place-eg, some set standards for meals, some for vending, some for all food in schools, and some are specific to sugar-sweetened beverages-a common feature is that they aim to restrict the availability of sugarsweetened beverages. Such policies have been implemented at the national, state or province, municipal, and school district levels; most of these policies are mandatory, although many examples of official guidelines for voluntary application also exist.

Evidence about the eff ects of restricting sugar-sweetened beverages on consumption comes mainly from the USA, where state-level bans have consistently led to decreased availability in schools, but the evidence for an effect on daily consumption has been mixed. ${ }^{95}$ Restrictions might be less eff ective if they do not include all sugar-sweetened beverages or are not comprehensive across the school environment. ${ }^{96}$ Where bans are comprehensive, they affect in-school purchasing of sugar-sweetened beverages but do not necessarily reduce overall consumption, since children can bring these beverages into school and consume them before and after school. ${ }^{96,97}$ These fi ndings suggest that a range of synergistic measures are needed both inside and outside schools, ${ }^{83,98}$ since preferences and habits for consumption of such beverages are already deeply entrenched. More evidence is also needed from low-income and middle-income countries, where a range of policies on school snacking, beverages, and meals have been instituted but no large-scale evaluations have been done so far.

\section{Marketing restrictions}

Efforts to reduce the exposure and power of marketing of soft drinks have been less widely implemented than the other policy actions reviewed here (figure 6). The UK, Ireland, and South Korea restrict advertising of sugarsweetened beverages as part of regulations on advertising of foods high in fat, sugar, and salt content, but these are applicable only to specific communications channels (mainly television). Iran is reported to have had a ban on all soft-drink advertising on television since 1994. Since 2007, France has required health messages on all food and drink advertising. On July 1, 2016, Chile will implement a new law to ban marketing to children of foods and beverages high in sugar, sodium, calories, or saturated fats, and will also require these banned products to have front-of-pack warnings. ${ }^{81,99}$ Evidence for the effect of marketing restrictions on consumption of sugar-sweetened beverages is not available; at present, the effect of comprehensive marketing bans, which are recommended as the most effective approach by WHO, ${ }^{100}$ cannot be assessed, since no country has comprehensively restricted all forms of marketing of sugar-sweetened beverages to children.

\section{Public awareness campaigns}

Several governments have also launched public awareness campaigns..$^{85}$ In New York City (NY, USA), the Department of Health set a precedent in 2009 with its Pouring on the Pounds campaign to reduce consumption of sugarsweetened beverages through the use of posters, videos, and slogans such as "Don't drink yourself fat". This campaign has been adapted for use in other US stateseg, the Choose Health LA Sugar Pack campaign in Los Angeles, CA. Sugary drinks have been included in public awareness campaigns in Australian states and territories, as part of the LiveLighter campaign; ${ }^{101}$ in 
England, where the Change4Life public health programme ran a social marketing campaign called Smart Swaps in January, 2014, to encourage alternatives to sugary drinks; ${ }^{102}$ and in Tonga, where the 2012 A Mouthful of Sugar campaign featured an image of a bottle of soda with a label reading "diabetes".

Evidence suggests that public awareness campaigns are effective at reducing consumption of unhealthy foods and drinks if they use several modes of communication and are run for a sustained period. ${ }^{103}$ However, few assessments specific to sugar-sweetened beverages have been done. One exception is the Choose Health LA Sugar Pack campaign, which increased the public's knowledge of sugar in drinks. In an evaluation of the campaign (which included a survey), more than $60 \%$ of respondents reported that they were likely or very likely to reduce their daily intake of sugary drinks. ${ }^{26}$

\section{Front-of-pack labelling}

Front-of-pack labels on food packages that show the levels of sugars have been adopted in several countries. In 2014, the Ecuadorian Government set a precedent by requiring so-called traffic light labels on packaged foods and drinks. The labels display the levels of sugar, fats, and salt with the colour codes: red (high), orange (medium), or green (low). This approach was first implemented in the UK, where voluntary guidelines were produced in 2006 and revised in 2013 by the government. The Chilean approach requires foods high in added sugar, sodium, and saturated fats to carry a warning label about ill-health effects, a requirement that will also be applied to advertising from July $1,2016 .{ }^{8}$ In some countries, the consumer packaged food and beverage industry has adopted an alternative approach of calorie labelling on a voluntary basis. Other labelling systems take a different approach by indicating healthier products, including products lower in sugar; examples are the Healthy Stars Rating labels in Australia and the Green Keyhole labels in Denmark, Norway, Sweden, and Iceland.

The effects of these front-of-pack labels on purchasing and consumption have yet to be fully evaluated..$^{104,105}$ Evidence suggests that these types of labels are easier to understand and interpret correctly than are traditional nutrient lists, but that their effect depends on the nature of the population, with highly educated groups and nutritionally aware shoppers being more likely to be responsive than others. ${ }^{105}$ Different types of labels seem to result in different responses..$^{106,107}$ One small US study specific to sugar-sweetened beverages suggests that provision of prominent caloric information was associated with reduced purchasing. ${ }^{108}$ Some evidence suggests that front-of-pack symbols can have a positive effect on reformulation of foods, and this effect has been shown in sugar-sweetened beverages specifically. ${ }^{109,110}$

\section{Reformulation and portion size reduction}

Although mandatory or voluntary targets to encourage reformulation of processed foods are fairly widespread around the world, these targets generally apply to salt and trans fats. ${ }^{111}$ Only France has made a concerted effort to set sugar reduction targets in foods and drinks; since 2001, it has been implementing a strategy that aims to reduce sugar consumption by $25 \%$, but this seems to apply to foods only (ie, excluding beverages). ${ }^{26}$ In New York City, efforts to introduce legislation on portion sizes of sugar-sweetened beverages in restaurants failed to be implemented. ${ }^{112}$

\section{Substitutes for sugar-sweetened beverages}

We also examined how policies deal with potential alternatives to sugar-sweetened beverages. This is important because such measures affect what people may choose to consume instead and therefore their overall caloric intake. ${ }^{113}$ Although from a public health standpoint, unsweetened or very lightly sweetened water milk, tea, and coffee are the best alternatives, ${ }^{43,114-116}$ policy makers need to make practical decisions about beverages for which the cardiometabolic effects are inconclusive. The difficulty of differentiating added sugars from natural sugars in front-of-pack labels also poses challenges for policy formulation.

For countries that have taxes on sugar-sweetened beverages or foods with added sugars, most tax according to the level of sugar in drinks or foods, and do not tax drinks with no caloric sweeteners or low-calorie sweeteners. France is a rare exception that includes drinks with low-calorie sweeteners, reportedly because no specific category in customs codification is dedicated to sodas. ${ }^{113}$ Results from one analysis suggest that this policy reduces the effectiveness of the tax because the prices of all drinks are increased, so that the relative differences between products remain unchanged. ${ }^{113}$ The preliminary assessment of the Mexican tax on sugarsweetened beverages, which does not include drinks with non-caloric sweeteners, shows a roughly $4 \%$ increase in purchases of untaxed beverages in 2014, which was mainly driven by an increase in the purchase of bottled plain water (data for tap water intake were not available). No concomitant increase has been reported in sales of $100 \%$ fruit juices (which are expensive), nor of drinks with low-calorie sweeteners (which are less well promoted than drinks with caloric sweeteners and are reportedly unpopular in the country ${ }^{117}$ ).

By contrast with tax policies, school policies-such as those in Queensland, Australia; France; and Brazil-tend to include beverages with low-calorie sweeteners in their restrictions on the basis that they are of minimal nutritional value and therefore have little contribution to school meals. ${ }^{118} 100 \%$ fruit juices are typically permitted with limited portion sizes (eg, 4 ounces [113 g] in the USA). In Mexico, the school food standards implemented in 2013 initially permitted fruit drinks; however, a preliminary analysis shows that carbonated sugar-sweetened beverages were simply replaced by beverages with equal caloric content. ${ }^{119}$ As a result, the Mexican Department of 
Education has now excluded fruit drinks and has proposed plans to provide potable water in schools with some of the proceeds from the sugar-sweetened beverage tax, although this policy has not been implemented.

Public awareness campaigns tend to promote drinks that are low in calories as alternatives. The slogan used in the New York City campaign in 2009 was "Go with water, seltzer or low-fat milk instead”. In England, the Smart Swaps campaign recommends water, drinks containing low-calorie sweeteners, and any drinks with no added sugar as potential swaps for sugar-sweetened beverages. ${ }^{102}$ The campaign in Tonga recommended substitution with water or coconut water. ${ }^{85}$

\section{Conclusion}

The evidence presented in this Personal View has four important policy implications. First, evidence that added sugars have adverse eff ects on weight gain and many cardiometabolic risks provides a rationale for government action. Sugar-sweetened beverages and processed food are major sources of added sugars in most countries. WHO has recommended the amount of added sugars be reduced in foods, but the evidence for the eff ectiveness of this recommendation is less clear than for that for sugarsweetened beverages; a clear policy priority should be to reduce intake of these beverages. Second, consumption of sugar-sweetened beverages is rising fastest in low-income and middle-income countries in Latin America, the Caribbean, Africa, the Middle East, Asia, and Oceania; therefore, action is urgently needed in these countries to reduce consumption of such beverages. Policies are also needed to continue to decrease the high levels of consumption in Australasia, North America, and western European countries. Third, although intakes of carbonated sugar-sweetened beverages might be stabilising or declining in some countries, governments need to be aware of the rising sales of sports, energy, and fruit drinks with added sugars, which also require policy attention. Fourth, the absence of a consensus on the evidence on beverages containing low-calorie sweeteners and fruit juices creates a practical conundrum for policy formulation. From a public health perspective, unsweetened or very lightly sweetened water, milk, tea, and coffee are appropriate substitutes, depending on context and age group, although policy makers still need to make practical decisions about how to treat drinks with low-calorie sweeteners and fruit juices in the design of policies to tackle consumption of sugar-sweetened beverages.

To conclude, many countries consume high levels of sugar-sweetened beverages, and others with lower intakes are seeing steep increases. We have also shown from trends data that consumption seems to be decreasing in countries with taxes on sugar-sweetened beverages (eg, Mexico, Finland, Hungary, and France). WHO, major scientific bodies, and most countries recognise the importance of reducing consumption of sugar-sweetened beverages to improve public health. The

\section{Search strategy and selection criteria}

We searched for publications on MEDLINE from Jan 1, 2000, to March 31, 2015. We did a selective review of published work on the effect of foods and beverages with added caloric sweeteners and low-calorie sweeteners on cardiometabolic outcomes, from the perspective of the evidence needed to inform policy, referencing key studies and the emergence of the evidence base over time to provide an up-to-date picture. This is not a systematic review but a Personal View in which we cite selected key reports and meta-analyses.

evaluation of not only sugar taxes, but also new marketing controls and front-of-pack labelling, is important and represents one of the next frontiers-namely, can these policies effectively reduce consumption of sugarsweetened beverages and intake of total added sugars?

\section{Contributors}

Both authors contributed equally to the text. BMP was responsible for the figures and tables on sweeteners; $\mathrm{CH}$ was responsible for the figures related to policies.

\section{Declaration of interests}

We declare no competing interests.

\section{Acknowledgments}

We thank the Robert Wood Johnson Foundation (grants 67506, 68793, 70017, 71837) and the US National Institutes of Health (grants R01DK098072 and CPC 5 R24 HD050924) for financial support. We thank Shu Wen Ng, Greg Bricker, Donna Miles, and the University of North Carolina Global Food Research Program for their exceptional help in creating the US measurement of caloric sweeteners and low-calorie sweeteners in the US food supply. We thank Chris Ford for all his work with the Euromonitor data. We also thank Frances L Dancy for administrative assistance and Denise Ammons for graphics support. We are grateful to WCRF International for continuing to update their NOURISHING policy database.

\section{References}

1 Ng SW, Ni Mhurchu C, Jebb SA, Popkin BM. Patterns and trends of beverage consumption among children and adults in Great Britain, 1986-2009. Br J Nutr 2012; 108: 536-51.

2 Sanigorski AM, Bell AC, Swinburn BA. Association of key foods and beverages with obesity in Australian schoolchildren. Public Health Nutr 2007; 10: 152-57.

3 Bray GA, Popkin BM. Dietary sugar and body weight: have we reached a crisis in the epidemic of obesity and diabetes? Health be damned! Pour on the sugar. Diabetes Care 2014; 37: 950-56.

4 Hu FB. Resolved: there is sufficient scientific evidence that decreasing sugar-sweetened beverage consumption will reduce the prevalence of obesity and obesity-related diseases. Obes Rev 2013; 14: 606-19.

5 The Lancet Diabetes \& Endocrinology. Sugar intake: lowering the bar. Lancet Diabetes Endocrinol 2015; 3: 305.

6 Bliss M. Rewriting medical history: Charles Best and the Banting and Best myth. J Hist Med Allied Sci 1993; 48: 253-74.

7 Yudkin J. Dietary fat and dietary sugar in relation to ischemic heart-disease and diabetes. Lancet 1964; 2: 4-5.

8 Yudkin J. Sweet and dangerous: the new facts about the sugar you eat as a cause of heart disease, diabetes, and other killers. New York: P H Wyden, 1972.

9 Mattes RD. Dietary compensation by humans for supplemental energy provided as ethanol or carbohydrate in fluids. Physiol Behav 1996; 59: 179-87.

10 DiMeglio DP, Mattes RD. Liquid versus solid carbohydrate: effects on food intake and body weight. Int J Obes Relat Metab Disord 2000; 24: 794-800. 
11 Mourao DM, Bressan J, Campbell WW, Mattes RD. Effects of food form on appetite and energy intake in lean and obese young adults. Int J Obes (Lond) 2007; 31: 1688-95.

12 DellaValle DM, Roe LS, Rolls BJ. Does the consumption of caloric and non-caloric beverages with a meal affect energy intake? Appetite 2005; 44: 187-93.

13 Lennerz BS, Alsop DC, Holsen LM, et al. Effects of dietary glycemic index on brain regions related to reward and craving in men. Am J Clin Nutr 2013; 98: 641-47.

14 Mattes RD, Popkin BM. Nonnutritive sweetener consumption in humans: effects on appetite and food intake and their putative mechanisms. Am J Clin Nutr 2009; 89: 1-14.

15 Te Morenga L, Mallard S, Mann J. Dietary sugars and body weight: systematic review and meta-analyses of randomised controlled trials and cohort studies. BMJ 2013; 346: e7492.

16 Te Morenga LA, Howatson AJ, Jones RM, Mann J. Dietary sugars and cardiometabolic risk: systematic review and meta-analyses of randomized controlled trials of the effects on blood pressure and lipids. Am J Clin Nutr 2014; 100: 65-79.

17 Anand SS, Hawkes C, de Souza RJ, et al. Global food consumption and its impact on cardiovascular disease: importance of solution focused on the globalized food system: a report from the workshop convened by the World Heart Federation. J Am Coll Cardiol 2015; 66: 1590-614.

18 Vartanian LR, Schwartz MB, Brownell KD. Effects of soft drink consumption on nutrition and health: a systematic review and meta-analysis. Am J Public Health 2007; 97: 667-75.

19 Singh GM, Micha R, Khatibzadeh S, et al. Estimated global, regional, and national disease burdens related to sugar-sweetened beverage consumption in 2010. Circulation 2015; 132: 639-66.

20 Malik VS, Popkin BM, Bray GA, Despres JP, Willett WC, Hu FB. Sugar-sweetened beverages and risk of metabolic syndrome and type 2 diabetes: a meta-analysis. Diabetes Care 2010; 33: 2477-83.

21 Imamura F, O'Connor L, Ye Z, et al. Consumption of sugar sweetened beverages, artificially sweetened beverages, and fruit juice and incidence of type 2 diabetes: systematic review, metaanalysis, and estimation of population attributable fraction. BMJ 2015; 351: h3576.

22 Lesser LI, Ebbeling CB, Goozner M, Wypij D, Ludwig DS. Relationship between funding source and conclusion among nutrition-related scientific articles. PLoS Med 2007; 4: e5.

23 Bes-Rastrollo M, Schulze MB, Ruiz-Canela M Martinez-Gonzalez MA. Financial conflicts of interest and reporting bias regarding the association between sugar-sweetened beverages and weight gain: a systematic review of systematic reviews. PLoS Med 2013; 10: e1001578.

24 Ebbeling CB, Feldman HA, Chomitz VR, et al. A randomized trial of sugar-sweetened beverages and adolescent body weight. N Engl J Med 2012; 367: 1407-16.

25 de Ruyter JC, Olthof MR, Seidell JC, Katan MB. A trial of sugar-free or sugar-sweetened beverages and body weight in children. N Engl J Med 2012; 367: 1397-406.

26 WCRF. Curbing global sugar consumption: effective food policy actions to help promote healthy diets and tackle obesity. London: World Cancer Research Fund International, 2015. http://www.wcrf. org/int/policy/our-policy-work/curbing-global-sugar-consumption (accessed July 11, 2015).

27 WHO. Guideline: sugars intake for adults and children. Geneva: World Health Organization, 2015.

28 Johnson RK, Appel LJ, Brands M, et al, on behalf of the American Heart Association Nutrition Committee of the Council on Nutrition, Physical Activity, and Metabolism and the Council on Epidemiology and Prevention. Dietary sugars intake and cardiovascular health: a scientific statement from the American Heart Association. Circulation 2009; 120: 1011-20.

29 McKiernan F, Hollis JH, Mattes RD. Short-term dietary compensation in free-living adults. Physiol Behav 2008; 93: 975-83.

30 Flood-Obbagy JE, Rolls BJ. The effect of fruit in different forms on energy intake and satiety at a meal. Appetite 2009; 52: 416-22.

31 Menke A, Casagrande S, Geiss L, Cowie CC. Prevalence of and trends in diabetes among adults in the United States, 1988-2012. JAMA 2015; 314: 1021-29.
32 Mursu J, Virtanen JK, Tuomainen T-P, Nurmi T, Voutilainen S. Intake of fruit, berries, and vegetables and risk of type 2 diabetes in Finnish men: the Kuopio Ischaemic Heart Disease Risk Factor Study. Am J Clin Nutr 2014; 99: 328-33.

33 Odegaard AO, Koh W-P, Arakawa K, Yu MC, Pereira MA. Soft drink and juice consumption and risk of physician-diagnosed incident type 2 diabetes: the Singapore Chinese Health Study. Am J Epidemiol 2010; 171: 701-08.

34 Muraki I, Imamura F, Manson JE, et al. Fruit consumption and risk of type 2 diabetes: results from three prospective longitudinal cohort studies. BMJ 2013; 347: f5001.

35 Bazzano LA, Li TY, Joshipura KJ, Hu FB. Intake of fruit, vegetables, and fruit juices and risk of diabetes in women. Diabetes Care 2008; 31: 1311-17.

36 Xi B, Li S, Liu Z, et al. Intake of fruit juice and incidence of type 2 diabetes: a systematic review and meta-analysis. PLoS One 2014; 9: e93471.

37 Piernas C, Tate DF, Wang X, Popkin BM. Does diet-beverage intake affect dietary consumption patterns? Results from the Choose Healthy Options Consciously Everyday (CHOICE) randomized clinical trial. Am J Clin Nutr 2013; 97: 604-11.

38 Dhingra R, Sullivan L, Jacques PF, et al. Soft drink consumption and risk of developing cardiometabolic risk factors and the metabolic syndrome in middle-aged adults in the community. Circulation 2007; 116: 480-88.

39 Lutsey PL, Steffen LM, Stevens J. Dietary intake and the development of the metabolic syndrome: the Atherosclerosis Risk in Communities study. Circulation 2008; 117: 754-61.

40 de Koning L, Malik VS, Rimm EB, Willett WC, Hu FB. Sugar-sweetened and artificially sweetened beverage consumption and risk of type 2 diabetes in men. Am J Clin Nutr 2011; 93: 1321-27.

41 Duffey KJ, Steffen LM, Van Horn L, Jacobs DR Jr, Popkin BM. Dietary patterns matter: diet beverages and cardiometabolic risks in the longitudinal Coronary Artery Risk Development in Young Adults (CARDIA) Study. Am J Clin Nutr 2012; 95: 909-15.

42 de Koning L, Malik VS, Kellogg MD, Rimm EB, Willett WC, Hu FB. Sweetened beverage consumption, incident coronary heart disease, and biomarkers of risk in men. Circulation 2012; 125: 1735-41, S1.

43 Tate DF, Turner-McGrievy G, Lyons E, et al. Replacing caloric beverages with water or diet beverages for weight loss in adults: main results of the Choose Healthy Options Consciously Everyday (CHOICE) randomized clinical trial. Am J Clin Nutr 2012; 95: 555-63.

44 Raben A, Vasilaras TH, Møller AC, Astrup A. Sucrose compared with artificial sweeteners: different effects on ad libitum food intake and body weight after $10 \mathrm{wk}$ of supplementation in overweight subjects. Am J Clin Nutr 2002; 76: 721-29.

45 Goran MI, Tappy L, Le K-A, Ulijaszek S. Dietary sugars and health. Oxford: Taylor and Francis, 2014.

46 Walker RW, Dumke KA, Goran MI. Fructose content in popular beverages made with and without high-fructose corn syrup. Nutrition 2014; 30: 928-35.

47 Ludwig DS. Examining the health effects of fructose. JAMA 2013; 310: 33-34.

48 Wolf A, Bray GA, Popkin BM. A short history of beverages and how our body treats them. Obes Rev 2008; 9: 151-64.

49 Bray GA, Nielsen SJ, Popkin BM. Consumption of high-fructose corn syrup in beverages may play a role in the epidemic of obesity. Am J Clin Nutr 2004; 79: 537-43.

50 Maersk M, Belza A, Stødkilde-Jørgensen H, et al. Sucrose-sweetened beverages increase fat storage in the liver, muscle, and visceral fat depot: a 6-mo randomized intervention study. Am J Clin Nutr 2012; 95: 283-89.

51 Stanhope KL, Havel PJ. Fructose consumption: recent results and their potential implications. Ann NY Acad Sci 2010; 1190: 15-24

52 Stanhope KL, Bremer AA, Medici V, et al. Consumption of fructose and high fructose corn syrup increase postprandial triglycerides, LDL-cholesterol, and apolipoprotein-B in young men and women. J Clin Endocrinol Metab 2011; 96: E1596-605.

53 Stanhope KL. Role of fructose-containing sugars in the epidemics of obesity and metabolic syndrome. Annu Rev Med 2012; 63: $329-43$. 
54 Johnson R, Moorthy SN, Padmaja G. Production of high fructose syrup from cassava and sweet potato flours and their blends with cereal flours. Food Sci Technol Int 2010; 16: 251-58.

55 Johnson RJ, Andrews P. Fructose, uricase, and the Back-to-Africa hypothesis. Evol Anthropol Issues News Rev (Melb) 2010; 19: 250-57.

56 Johnson RJ, Murray R. Fructose, exercise, and health. Curr Sports Med Rep 2010; 9: 253-58.

57 Johnson RJ, Nakagawa T, Sanchez-Lozada LG, et al. Sugar, uric acid, and the etiology of diabetes and obesity. Diabetes 2013; 62: 3307-15.

58 Johnson RJ, Sanchez-Lozada LG, Nakagawa T. The effect of fructose on renal biology and disease. J Am Soc Nephrol 2010; 21: 2036-39.

59 Johnson RJ, Segal MS, Sautin Y, et al. Potential role of suga (fructose) in the epidemic of hypertension, obesity and the metabolic syndrome, diabetes, kidney disease, and cardiovascular disease. Am J Clin Nutr 2007; 86: 899-906.

60 Dekker MJ, Su Q, Baker C, Rutledge AC, Adeli K. Fructose: a highly lipogenic nutrient implicated in insulin resistance, hepatic steatosis, and the metabolic syndrome. Am J Physiol Endocrinol Metab 2010; 299: E685-94.

61 Lustig RH. Fructose: it's "alcohol without the buzz". Adv Nutr 2013; 4: $226-35$

62 Lustig RH, Schmidt LA, Brindis CD. Public health: the toxic truth about sugar. Nature 2012; 482: 27-29.

63 Mueller NT, Odegaard A, Anderson K, et al. Soft drink and juice consumption and risk of pancreatic cancer: the Singapore Chinese Health Study. Cancer Epidemiol Biomarkers Prev 2010; 19: 447-55.

64 Sakurai M, Nakamura K, Miura K, et al. Sugar-sweetened beverage and diet soda consumption and the 7-year risk for type 2 diabetes mellitus in middle-aged Japanese men. Eur J Nutr 2014; 53: 251-58

65 Hernández-Cordero S, Barquera S, Rodríguez-Ramírez S, et al. Substituting water for sugar-sweetened beverages reduces circulating triglycerides and the prevalence of metabolic syndrome in obese but not in overweight Mexican women in a randomized controlled trial. J Nutr 2014; 144: 1742-52.

66 Davis JN, Whaley SE, Goran MI. Effects of breastfeeding and low sugar-sweetened beverage intake on obesity prevalence in Hispanic toddlers. Am J Clin Nutr 2012; 95: 3-8.

67 Davis JN, Ventura EE, Weigensberg MJ, et al. The relation of sugar intake to beta cell function in overweight Latino children. Am J Clin Nutr 2005; 82: 1004-10.

68 Davis JN, Alexander KE, Ventura EE, et al. Associations of dietary sugar and glycemic index with adiposity and insulin dynamics in overweight Latino youth. Am J Clin Nutr 2007; 86: 1331-38.

69 Schwimmer JB, Deutsch R, Kahen T, Lavine JE, Stanley C, Behling C. Prevalence of fatty liver in children and adolescents. Pediatrics 2006; 118: 1388-93.

70 Zhou Y, Du S, Su C, Zhang B, Wang H, Popkin BM. The food retail revolution in China and its association with diet and health Food Policy 2015; 55: 92-100.

71 Popkin BM. Nutrition, agriculture and the global food system in low and middle income countries. Food Policy 2014; 47: 91-96.

72 Reardon T, Timmer CP, Barrett CB, Berdegue JA. The rise of supermarkets in Africa, Asia, and Latin America. Am J Agric Econ 2003; 85: 1140-46.

73 Reardon T, Timmer CP, Minten B. Supermarket revolution in Asia and emerging development strategies to include small farmers. Proc Natl Acad Sci USA 2012; 109: 12332-37.

74 Reardon T, Chen KZ, Minten B, et al. The quiet revolution in Asia's rice value chains. Ann NY Acad Sci 2014; 1331: 106-18.

75 Ng SW, Slining MM, Popkin BM. Use of caloric and noncaloric sweeteners in US consumer packaged foods, 2005-2009. J Acad Nutr Diet 2012; 112: 1828-34.

76 Ng SW, Slining MM, Popkin BM. Turning point for US diets? Recessionary effects or behavioral shifts in foods purchased and consumed. Am J Clin Nutr 2014; 99: 609-16.

77 Arantxa Colchero M, Popkin BM, Rivera JA, Ng SW. Beverage purchases from stores since the start of the Mexican sugar-sweetened beverage excise tax: a year out. BMJ (in press).

78 Euromonitor. Euromonitor International. 2014. http://www. euromonitor.com/ (accessed March 30, 2015).

79 Euromonitor International. Passport Nutrition. 2015. http://www. euromonitor.com/ (accessed April 5, 2015).
80 Basu S, Yoffe P, Hills N, Lustig RH. The relationship of sugar to population-level diabetes prevalence: an econometric analysis of repeated cross-sectional data. PLoS One 2013; 8: e57873.

81 Corvalán C, Reyes M, Garmendia ML, Uauy R. Structural response to the obesity and non-communicable diseases epidemic: the Chilean Law of Food Labeling and Advertising. Obes Rev 2013 14 (suppl 2): 79-87.

82 Kleiman S, Ng SW, Popkin B. Drinking to our health: can beverage companies cut calories while maintaining profits? Obes Rev 2012; 13: $258-74$

83 Thow AM, Hawkes C. Global sugar guidelines: an opportunity to strengthen nutrition policy. Public Health Nutr 2014; 17: 2151-55.

84 Hawkes C, Jewell J, Allen K. A food policy package for healthy diets and the prevention of obesity and diet-related non-communicable diseases: the NOURISHING framework. Obes Rev 2013; 14 (suppl 2): 159-68.

85 WCRF International. NOURISHING framework. London: World Cancer Research Fund, 2015. http://www.wcrf.org/int/policy/ nourishing-framework (accessed July 10, 2015)

86 Brownell KD, Farley T, Willett WC, et al. The public health and economic benefits of taxing sugar-sweetened beverages. N Engl J Med 2009; 361: 1599-605.

87 Snowdon W, Thow AM. Trade policy and obesity prevention: challenges and innovation in the Pacific Islands. Obes Rev 2013; 14 (suppl 2): 150-58.

88 Bíró A. Did the junk food tax make the Hungarians eat healthier? Food Policy 2015; 54: 107-15.

89 WHO Regional Office for Europe (Nutrition Physical Activity and Obesity Programme). Using price policies to promote healthier diets. Brussels: WHO European Regional Office, 2015 http://www.euro.who.int/_data/assets/pdf_file/0008/273662/ Using-price-policies-to-promote-healthier-diets.pdf?ua $=1$ (accessed Oct 28, 2015).

90 Richards TJ, Patterson PM, Tegene A. Obesity and nutrient consumption: a rational addiction? Contemp Econ Policy 2007; 25: 309-24.

91 Zhen C, Wohlgenant MK, Karns S, Kaufman P. Habit formation and demand for sugar-sweetened beverages. Am J Agric Econ 2011; 93: 175-93.

92 Becker GS, Murphy KM. A theory of rational addiction. J Polit Econ 1988; 96: 675-700.

93 Grossman M, Chaloupka FJ. The demand for cocaine by young adults: a rational addiction approach. $J$ Health Econ 1998; 17: 427-74.

94 Hawkes C. The worldwide battle against soft drinks in schools. Am J Prev Med 2010; 38: 457-61.

95 Chriqui JF, Pickel M, Story M. Influence of school competitive food and beverage policies on obesity, consumption, and availability: a systematic review. JAMA Pediatr 2014; 168: 279-86.

96 Taber DR, Chriqui JF, Vuillaume R, Chaloupka FJ. How state taxes and policies targeting soda consumption modify the association between school vending machines and student dietary behaviors: a cross-sectional analysis. PLoS One 2014; 9: e98249.

97 Cullen KW, Watson K, Zakeri I. Improvements in middle schoo student dietary intake after implementation of the Texas Public School Nutrition Policy. Am J Public Health 2008; 98: 111-17.

98 ChangeLab Solutions. Sugar-sweetened beverages playbook. ChangeLab Solutions, 2013. http://changelabsolutions.org/ publications/SSB-playbook (accessed July 12, 2015)

99 Republica of Chile. Modifica Decreto Supremo No 977, DE 1996, Relglamento Sanitrario de los Alimentos (Regulation for food safety). 918813 (no 41193). Santiago: Republic of Chile printing office, 2015: 1-12 (in Spanish).

100 WHO. Set of recommendations on the marketing of foods and non alcoholic beverages to children. Geneva: World Health Organization, 2010. http://apps.who.int/iris/bitstream/10665/44416 /1/9789241500210_eng.pdf (accessed Nov 20, 2015).

101 LiveLighter. About sugary drinks. LiveLighter, 2015. https:// livelighter.com.au/The-Facts/About-Sugary-Drinks (accessed July 11, 2015).

102 Change for Life. Let's make some sugar swaps! 2015. http://www. nhs.uk/Change4Life/Pages/low-sugar-healthy-snacks.aspx (accessed July 11, 2015). 
103 Mozaffarian D, Afshin A, Benowitz NL, et al, on behalf of the American Heart Association Council on Epidemiology and Prevention, Council on Nutrition, Physical Activity and Metabolism, Council on Clinical Cardiology, Council on Cardiovascular Disease in the Young, Council on the Kidney in Cardiovascular Disease, Council on Peripheral Vascular Disease, and the Advocacy Coordinating Committee. Population approaches to improve diet, physical activity, and smoking habits: a scientific statement from the American Heart Association. Circulation 2012; 126: 1514-63.

104 Roodenburg AJ, Popkin BM, Seidell JC. Development of international criteria for a front of package food labelling system: the International Choices Programme. Eur J Clin Nutr 2011; 65: 1190-200.

105 Hawkes C, Smith TG, Jewell J, et al. Smart food policies for obesity prevention. Lancet 2015; 385: 2410-21.

106 Emrich TE, Qi Y, Mendoza JE, Lou W, Cohen JE, L'abbé MR. Consumer perceptions of the Nutrition Facts table and front-of-pack nutrition rating systems. Appl Physiol Nutr Metab 2014; 39: 417-24.

107 Roberto CA, Bragg MA, Seamans MJ, Mechulan RL, Novak N, Brownell KD. Evaluation of consumer understanding of different front-of-package nutrition labels, 2010-2011. Prev Chronic Dis 2012; 9: E149.

108 Bleich SN, Barry CL, Gary-Webb TL, Herring BJ. Reducing sugar-sweetened beverage consumption by providing caloric information: how Black adolescents alter their purchases and whether the effects persist. Am J Public Health 2014; 104: 2417-24.

109 Vyth EL, Steenhuis IH, Roodenburg AJ, Brug J, Seidell JC. Front-of-pack nutrition label stimulates healthier product development: a quantitative analysis. Int J Behav Nutr Phys Act 2010; 7: 65.

110 Piernas C, Ng SW, Popkin B. Trends in purchases and intake of foods and beverages containing caloric and low-calorie sweeteners over the last decade in the United States. Pediatric Obes 2013; 8: 294-306.
111 Webster J, Trieu K, Dunford E, Hawkes C. Target salt 2025: a global overview of national programs to encourage the food industry to reduce salt in foods. Nutrients 2014; 6: 3274-87.

112 New York City Department of Health and Mental Hygiene. Maximum Size For Sugary Drinks: Proposed Amendment of Article 81. New York City, NY: Department of Health and Mental Hygiene, 2012: 16.

113 ECSIP Consortium. Food taxes and their impact on competitiveness in the agri-food sector. Rotterdam: European Competitiveness and Sustainable Industrial Policy Consortium, 2014. http://ec.europa. eu/DocsRoom/documents/5827/attachments/1/translations/en/ renditions/pdf (accessed Oct 28, 2015).

114 Popkin BM, Armstrong LE, Bray GM, Caballero B, Frei B, Willett WC. A new proposed guidance system for beverage consumption in the United States. Am J Clin Nutr 2006; 83: 529-42.

115 Popkin BM, D'Anci KE, Rosenberg IH. Water, hydration, and health. Nutr Rev 2010; 68: 439-58.

116 Daniels MC, Popkin BM. Impact of water intake on energy intake and weight status: a systematic review. Nutr Rev 2010; 68: 505-21.

117 Stern D, Piernas C, Barquera S, Rivera JA, Popkin BM. Caloric beverages were major sources of energy among children and adults in Mexico, 1999-2012. J Nutr 2014; 144: 949-56.

118 Queensland Department of Education and the Arts, Queensland Health. Smart Choices: healthy food and drink supply strategy for Queensland schools. 2004. http://education.qld.gov.au/schools/ healthy/docs/smart-choices-strategy.pdf (accessed July 11, 2015).

119 Barquera S, Tolentino M, Safdie M, Levesque L. National guidelines for healthy nutrition in Mexican schools: an independent preliminary evaluation. Obes Rev 2014; 15 (suppl 2): 258 (abstr). 